\title{
Drombeg Stone Circle, Ireland, analyzed with respect to sunrises and lithic shadow-casting for the eight traditional agricultural festival dates and further validated by photography
}

\author{
G. Terence Meaden \\ Kellogg College, Oxford University, 62 Banbury Road, Oxford, U.K. Email: terencemeaden01@ gmail.com
}

\begin{abstract}
:
A new survey of Drombeg Stone Circle and accurate analysis of shadow effects beginning at particular sunrises of the calendar year has led to a breakthrough in the understanding of lithic symbolism and the intentions behind the construction of this and other Irish monuments including Knowth and Newgrange that also have astronomical alignments.

At Drombeg specific standing stones play critical roles at sunrise for all eight of the festival dates as known traditionally and historically for agricultural communities and as now inferred for prehistoric times following the present observation-based analysis.

Crucial for Drombeg in the summer half of the year is the positioning of a tall straight-sided portal stone such that its shadow at midsummer sunrise encounters an engraving on the recumbent stone diametrically opposite. During subsequent minutes the shadow moves away allowing the light of the sun to fall on the carved symbol. It is the same for sunrises at Beltane (May Day), Lughnasadh (Lammas), and the equinoxes when shadows from other perimeter stones achieve the same coupling with the same image, each time soon replaced by sunlight. For the winter half of the year which includes dates for Samhain, the winter solstice and Imbolc, the target stone for shadow reception at sunrise is a huge lozenge-shaped megalith, artificially trimmed. Moreover, for 22 March and 21 September there is notable dramatic action by shadow and light between a precisely positioned narrow pillar stone and the lozenge stone.

As a result, at sunrise at Drombeg eight calendrical shadow events have been witnessed and photographed. This attests to the precision of Neolithic planning that determined the stone positions, and demonstrates the antiquity of the calendar dates for these traditional agricultural festivals. Discussion is held as to what the concept of shadow casting between shaped or engraved stones at the time of sunrise may have meant in terms of lithic symbolism for the planners and builders. This leads to a possible explanation in terms of the ancient worldview known as the hieros gamos or the Marriage of the Gods between Sky and Earth.
\end{abstract}

Keywords: Drombeg; hieros gamos; Knowth; Neolithic calendar; Newgrange; solstice sunrises

Published by the School of History, Classics and Archaeology, University of Edinburgh ISSN: 2055-0472. URL: http://journals.ed.ac.uk/lithicstudies/

This work is licensed under a Creative Commons Attribution 2.5 UK: Scotland License. 


\section{Introduction}

During the 2500 years of the Neolithic and Early Bronze Age of Britain and Ireland, megaliths played a huge role in the communal lives of the early farming peoples who raised and used the stones.

An early practice was the preparation of a sacred area of land by digging a circular ditch thus creating a contiguous circular bank. This was the birth of a simple earthen monument termed a henge (like the Priddy Circles in Somerset). Introducing a ring of vertical timbers improved and emphasized the visual concept whether set inside a ditch-and-bank ring (as at Woodhenge) or used alone (as at Sarn-y-bryn-caled (Powys) and Seahenge (Norfolk)). An extension of the idea led to the raising of stones in a circle, with or without a henge because this provided longtime endurance with enhanced dramatic beauty as at Drombeg or majesty as at Stonehenge.

Stones were often selected for the shape of their lithic outline (as at Drombeg and Avebury) or for natural marks on them resulting from geological processes (Drombeg, Stone 1). Sometimes, shapes were improved by tooling (e.g., Stonehenge) to satisfy criteria deemed important to the sculptors - while at times, symbols were carved on selected stones (as extensively at Knowth and Newgrange). Additionally, alignments to solar risings or settings were featured, sometimes in relation to a standing stone positioned outside the monument. This includes Stonehenge (Cleal et al. 1995: 269-270) and Knowth (Eogan 1986: 47, 65, Plates 9 and 15). In this paper examples are introduced and explained through advances made by the present research at Drombeg.

Best progress at interpreting the ancient meanings comes from studying stone circles that are complete or little damaged. Drombeg Stone Circle is an appropriate candidate because most of its principal stones have survived and remain in position.

The foremost earlier work achieved at Drombeg was that of the excavator Fahy in 195758. Although his paper (Fahy 1959) is primarily about the details of the excavation, he made helpful interpretation too. Fahy's numbering system for the 17 circumferential stones is used in the present paper.

\section{Methodology}

Drombeg Stone Circle stands within two kilometres of the ocean near Glandore in County Cork, south-west Ireland (Figure 1). One of the 17 circumferential stones is recumbent. The latter bears engraved rock art symbols, while portal Stone 1 has natural images resulting from geological processes. These are discussed along with their relationship to the rising sun and the positions of other stones. Shapes are discussed for their outline lithic symbolism and positioned settings. Most important are a huge lozenge-shaped megalith and adjacent pillar stone whose outlines were meaningfully modified and positioned to work at the equinoctial sunrises. Helpful comparisons are made with near-equinoctial stones at Knowth.

Research visits were made at various times of the day for study and surveying, because of which it came to be realized that the crucial times of day that could help in resolving the meanings of the design scheme were at sunrise on certain dates of the traditional agricultural year. Corroboration by photography was achieved with a Sony high-quality single-lens digital reflex camera.

The previously best-known astronomical alignment at Drombeg is that observed at the winter solstice, when the sun sets into a prominent notch on the south-western horizon. The portal stones, numbered 1 and 17 by Fahy (1959), each stand two metres high and face outwards to the north-east or inwards towards the south-west. The sunset alignment bisects the gap between these stones, crosses the centre of the circle, bisects the recumbent stone, and 
continues to the $\mathrm{V}$-notch on the hill half-a-kilometre distant where the sun sets in midwinter week (Figure 2). Somerville (1909) was first to record this in print.

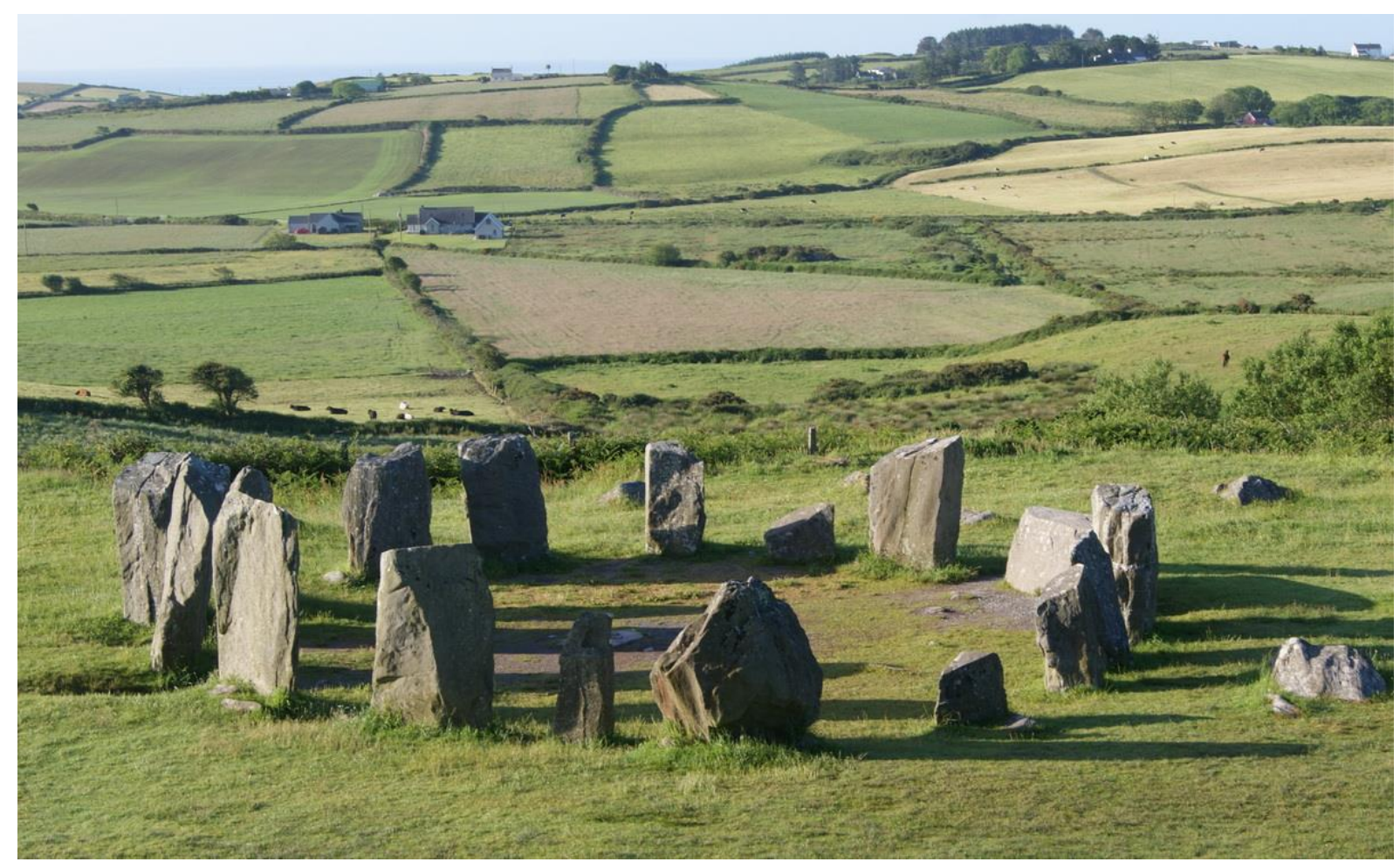

Figure 1. South-eastward view of the Drombeg stones an hour after sunrise, 19 June 2013. Author's photograph.

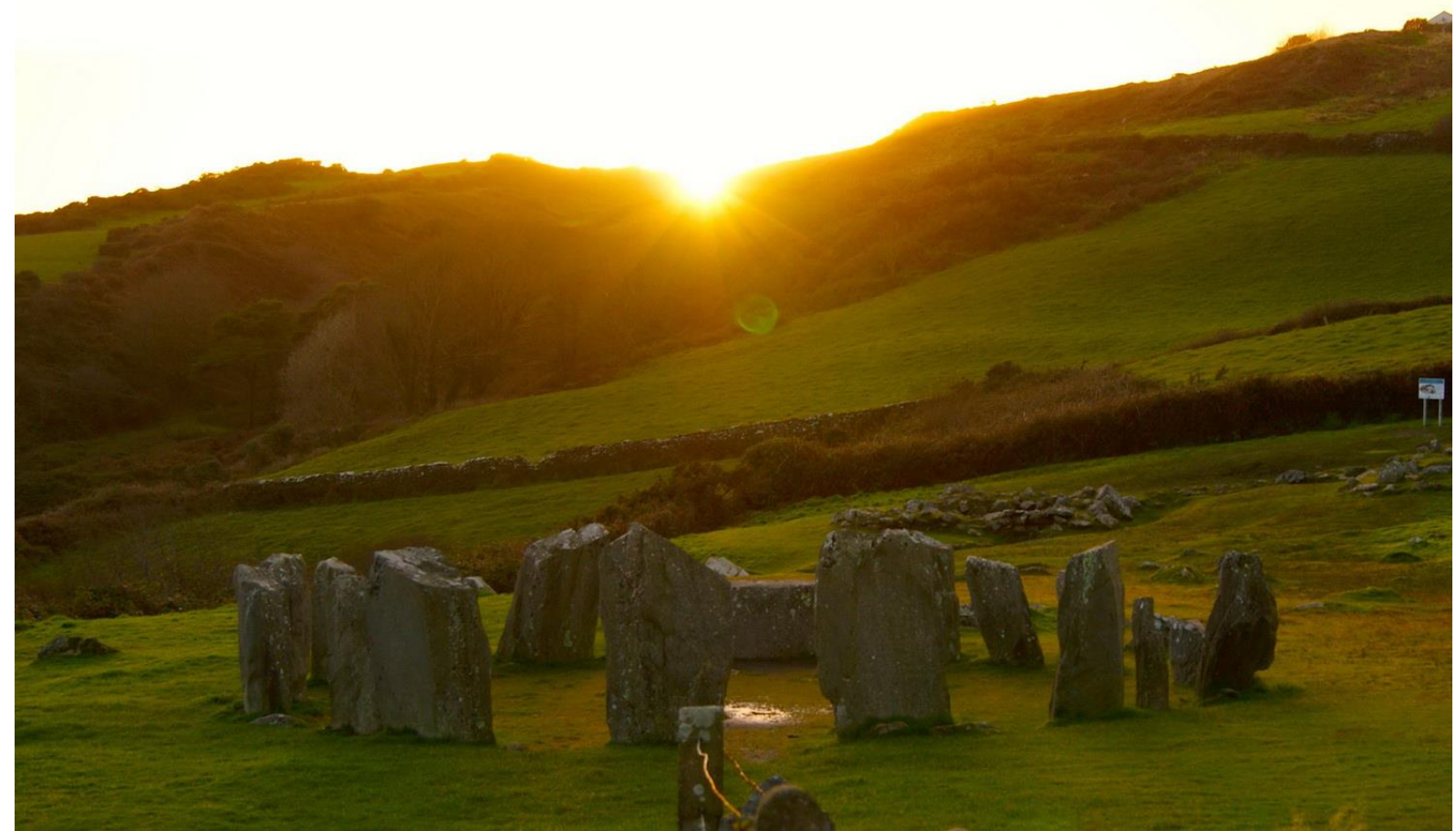

Figure 2. The sun setting into the hillside V-notch in line with the recumbent stone, close to the winter solstice 2012. Author's photograph. 


\subsection{The plan of Drombeg Stone Circle}

It was essential to have an accurate plan of the stone circle, so a new survey was carried out by the author (Figure 3). The 10 crucial perimeter stones at Drombeg have specific features due to their shape or position, and are the stones that take part in the action. In the plan these are shaded. Tallest are the straight-sided portal Stones 1 and 17, each two metres high.

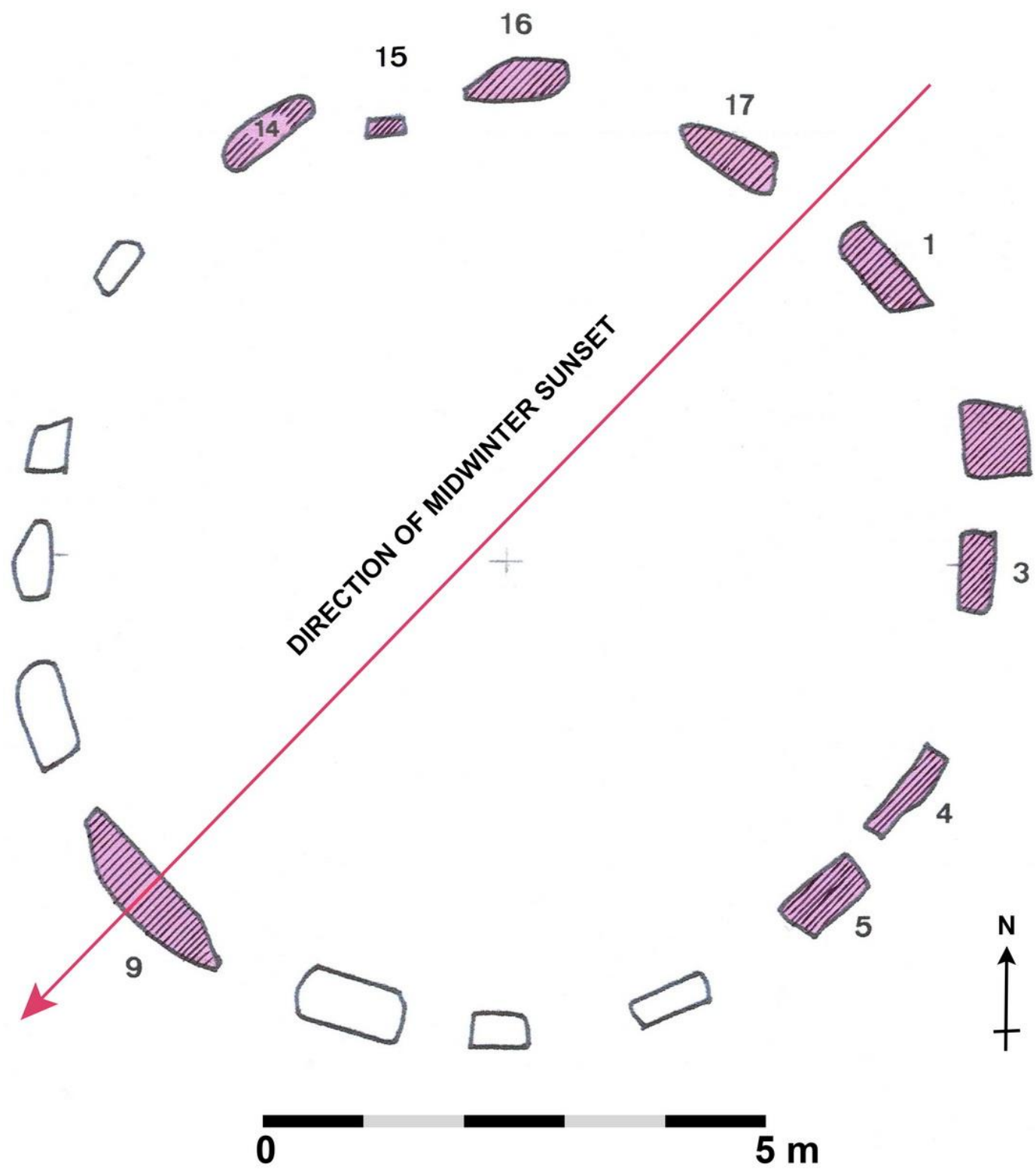

Figure 3. The author's 2012 survey of the stones of Drombeg. The functional stones discussed in the text as calendar stones are shaded. The ceremonial axis bisects the gap between the tall entry portals (Stones 17 and 1) and the art-bearing recumbent Stone 9. Note how the narrow pillar Stone 15 is deliberately offset. Reasons for this are discussed in Sections 3.4 and 4.4.

\subsection{A general note on ancient calendars}

It is demonstrated in this paper that particular megaliths at Drombeg were selected for size and shape and precisely positioned such that depending on season the rising sun would cast light on them allowing their shadows to fall upon other placed stones. A range of specific, recognizable, action spectacles results for certain dates of the calendar year. 
On the basis of there being 365 days in the year, it is appropriate to consider the operation of a day-counting calendar in which 21 December is regarded as Day 1 and 20 December as Day 365.

By quartering the full year, Day 92 is found to be 22 March, Day 183 is 21 June, and Day 275 is 21 September. These provide the calendar dates for the spring first quarter day, the midsummer solstice, and the autumn third quarter day respectively. It is important to note that the prehistoric people probably did not define the equinoxes in the way that we do - namely, as precisely equal day, equal night. This is largely because they had no clocks divided into minutes, whereas the day-counting method lends itself to a straightforward division of the 365-day calendar and resolves the equinoctial day-selection conundrum (Heggie 1981: 91; Ruggles 1999: 148-150).

Bisection of the foregoing four dates gives the cross-quarter dates that we call 5 February, 6 May, 6 August and 5 November. The resulting eight dates are 45 to 46 days apart. It establishes and justifies a practical calendar for Drombeg and other prehistoric sites based on the cosmic cycle. Communities only needed a sky-watcher to maintain a day count on their behalf throughout the year - for example, by using a tally stick that was marked daily. The author has constructed and used such a tally stick cut with 92 notches for experimental day marking through the entire year. By this means any or all of the eight principal calendar dates could be ascertained and encoded into the stones of Britain and Ireland's stone circles, as demonstrated by this research for Drombeg.

Indeed, it is proposed and it has been found that these are the eight relevant dates for best witnessing effects at sunrise at Drombeg under clear-sky conditions. The modern observer should be aware that minor differences in shadow production and timing can result depending on by how many days the optimum dates are missed due to obscured sunrises.

\section{Description of the principal stones}

Before dealing with the phenomena at sunrises on the dates of the eight traditional agricultural fairs and festivals, the defining features of the image-bearing stones and shaped symbol stones are described.

Interpretation of the Drombeg images and their interaction with the rising sun (Sections 3.1 and 3.2), as also their shapes (Sections 3.3 and 3.4), may provide insight into the beliefs of the community.

\subsection{Recumbent megalith}

Stone 9 with its flat upper surface lies recumbent. It stands on the south-western arc of the circle (Figures 1, 2, 3, and 4), nearly $210 \mathrm{~mm}$ long, $90 \mathrm{~mm}$ above ground level, and up to $45 \mathrm{~mm}$ thick.

One cup mark, diameter $50 \mathrm{~mm}$, is neatly round and shallow. A second cup mark is elongated, $92 \mathrm{~mm}$ by $64 \mathrm{~mm}$, and $19 \mathrm{~mm}$ deep.

Nearby is a trapezoidal line-carving $298 \mathrm{~mm}$ long (Figure 4, Figure 5). The outline is 184 $\mathrm{mm}$ wide at one end and $100 \mathrm{~mm}$ wide at the narrow end, the boundary being a pecked groove 6 to $8 \mathrm{~mm}$ deep. It encloses another cup mark pecked into a natural fissure that elongates the artificial depression medially. Although one can never be sure what the sculptor meant by this, one may suggest that the feature as a whole could have the character of a vulva which, by comparative traditional symbology (compare with Figure 6 for Palaeolithic examples), helps to attribute a feminine quality to the stone. Neolithic examples of this type of carving exist too. 


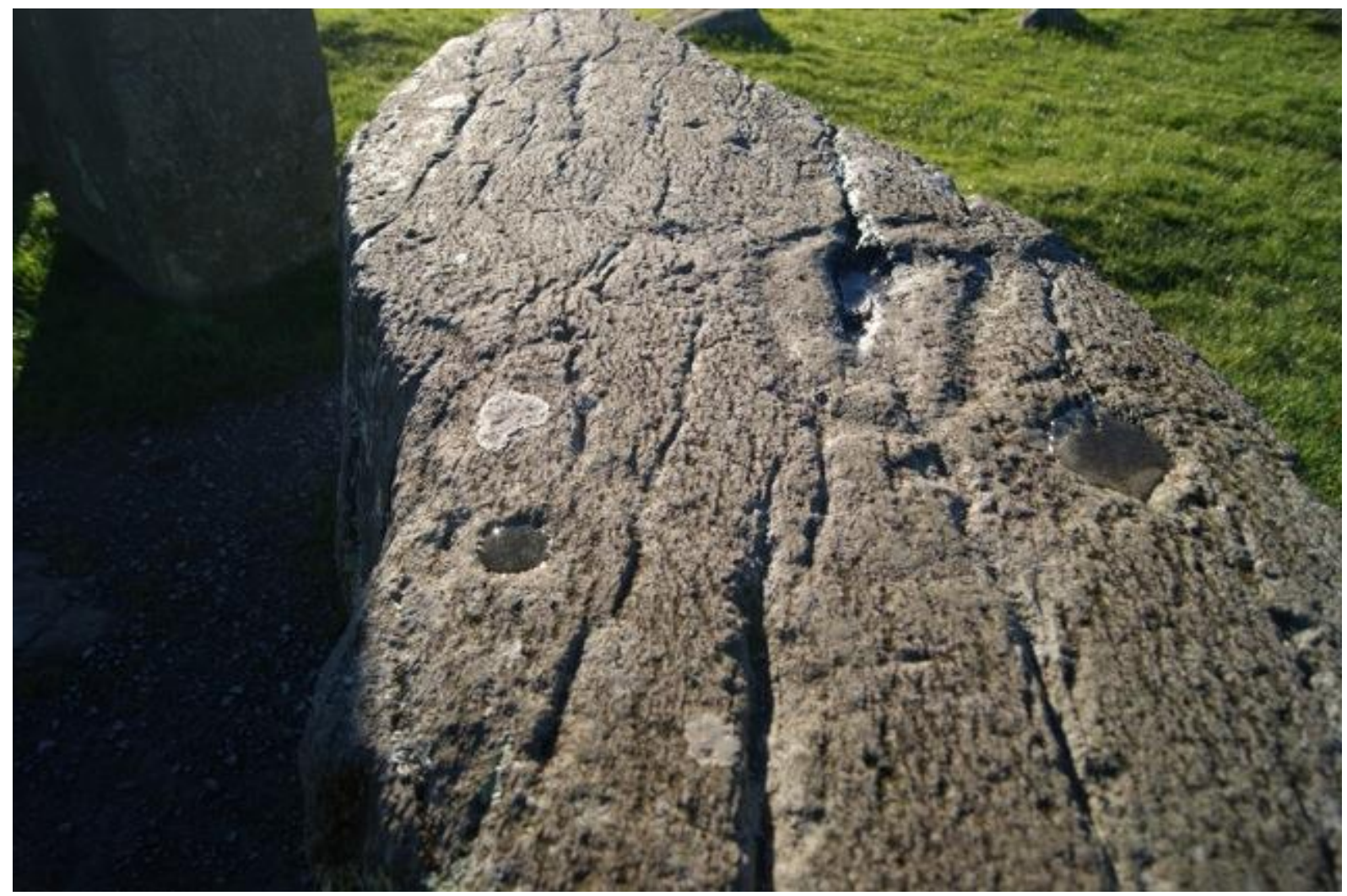

Figure 4. The flat upper surface of the recumbent stone, Stone 9, looking south-east with rock-cut images of two cup marks and a suggested vulva. The next figure is a tracing of these features as viewed from the opposite direction. Author's photograph.

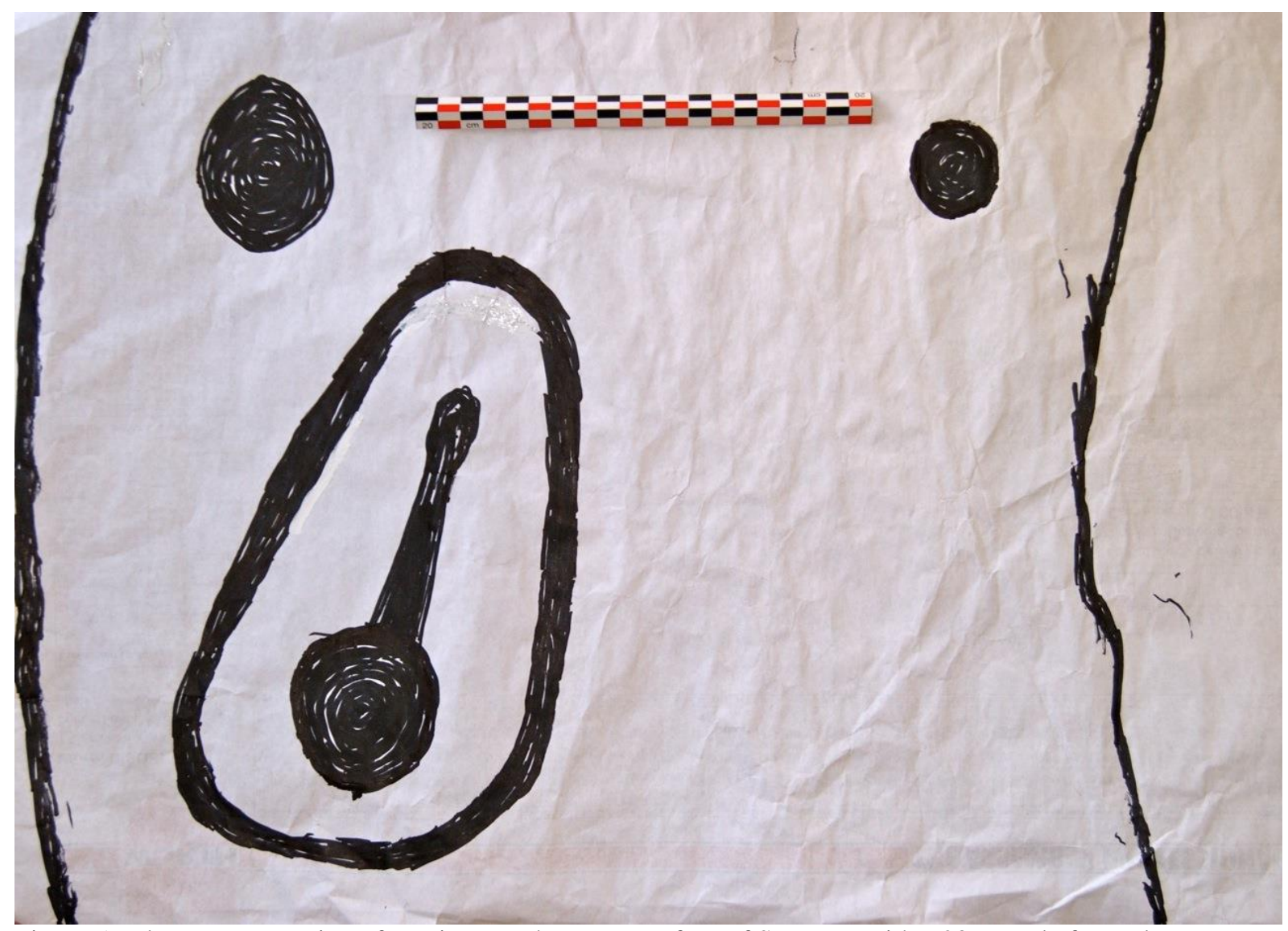

Figure 5. Ink-on-paper tracing of carvings on the upper surface of Stone 9 - with a $20 \mathrm{~cm}$ rule for scale. 

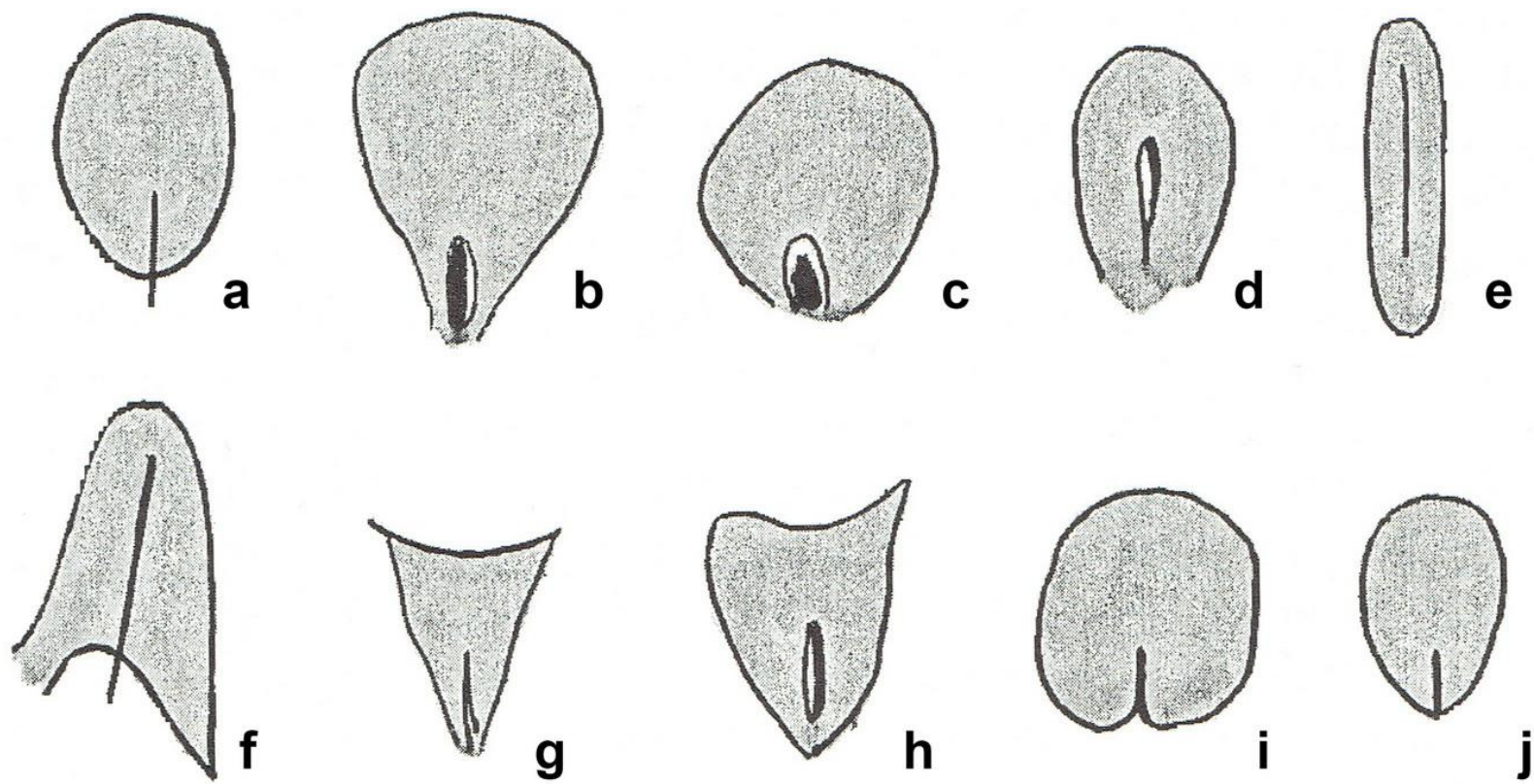

Figure 6. Carved vulvas: L'Abri Blanchard (a, b. c), La Ferrassie, Dordogne (d, e, h), El Castillo (f), Pergouset (g), Laussel (i), and Lalinde (j).

Additionally, there are two arcs of unknown meaning pecked towards the south-eastern end of the stone. All features were pecked by secondary percussion.

\subsection{Portal Stone 1}

Portal Stone 1 has undulating geomorphic features on its north-eastern outer side that are not artificial. This may imply that the planners favoured the stone if they had discerned in this a possibly anthropomorphic image (Figure 7a) which they perhaps interpreted through mythology. The form is not dissimilar to the outline of the back of a human image (Figure $7 \mathrm{~b}$ ) located, as it were, partly inside the stone and yet as if emerging from it. This is the only stone that bears any natural image, so perhaps it was set at this location because of perceived anthropomorphism and because this position on the circle's perimeter had some other aspect that was considered significant. Whatever else, this exterior side of Portal Stone 1 is turned to the local midsummer sunrise, while its opposite side - the internal side - faces the recumbent Stone 9 and midwinter sunset.

The other portal stone - similarly tall and narrow - bears an ithyphallic image (Figure 8).

\subsection{The lozenge-shaped megalith}

Stone 14 is a three-tonne boulder, lozenge shaped, standing on a point (Figure 9). One edge has been artificially improved. Fahy (1959: 5) writes that the stone is "a large, lozengeshaped boulder rather flat on its inner face but heavily bulbous on its outer or northern face. Three sides of the lozenge appeared to be natural edges but the upper right hand side had been produced by breaking the boulder along a joint plane".

Keiller and Piggott (1936: 420), Smith (1965: 19; 7, 251), Gimbutas (1989; 1991) and Meaden (1999: 3-6; 2008: 13-15) explain why traditionally the lozenge shape suggests femininity. Drombeg excavator Fahy (1959: 20-21) writes thus: "Lozenge shaped stones associated with pillar stones have been recognized at Avebury (citing Childe (1952: 102) who says "they are clearly male and female symbols") and are taken to represent or to be symbolical of the male and female sexes and to be connected with a fertility cult." Smith (1965: 251) writes similarly with regard to Avebury saying that if the stones "do indeed 
represent male and female symbols, the implication must be that the monuments were dedicated to a fertility cult."
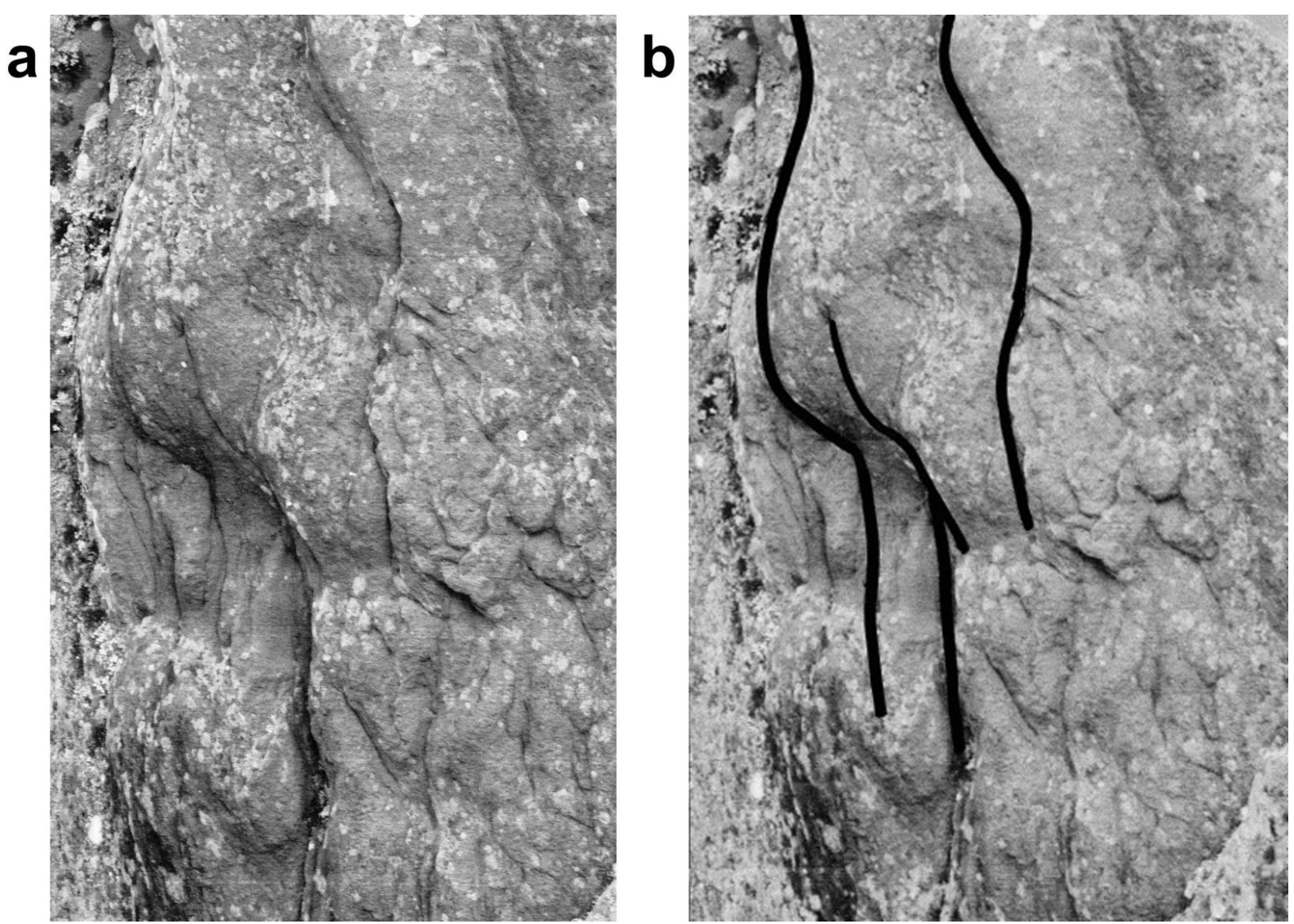

Figure 7. a. Stone 1 with natural contours that could be viewed as an anthropomorphic image. Author's photograph. $b$. The shape of the image is here emphasised in a manner that could have been done in prehistoric times using charcoal, chalk or red ochre (the latter is known for prehistoric Scandinavia). The image gives the impression of a human form within the stone as if emerging from it. Author's photograph.
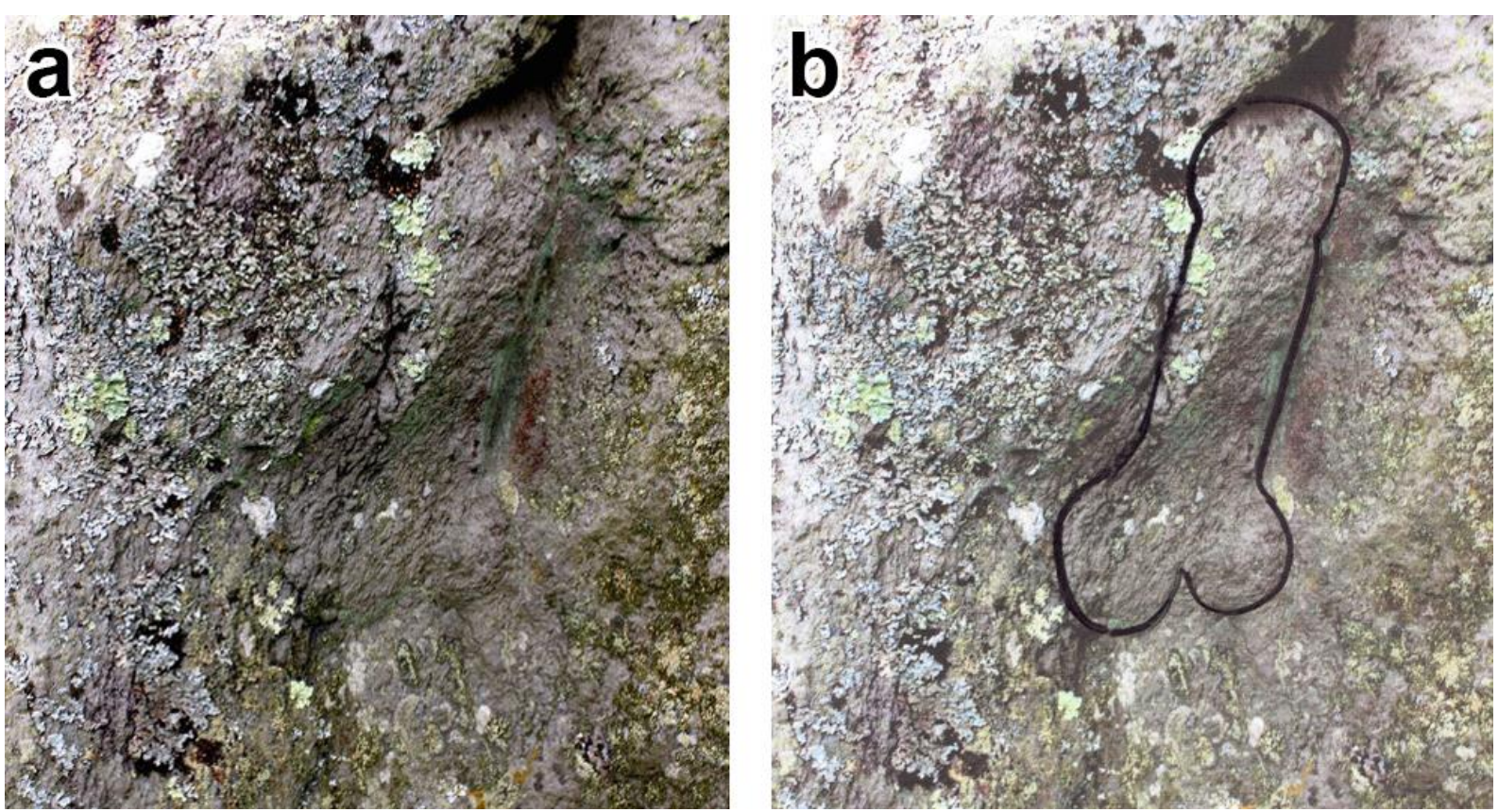

Figures $8 \mathrm{a}$ and $8 \mathrm{~b}$. An ithyphallic image on portal stone 17. The shadow of this tall male stone falls upon the female lozenge stone 14 at the quasi-equinoxes. Author's photographs. 


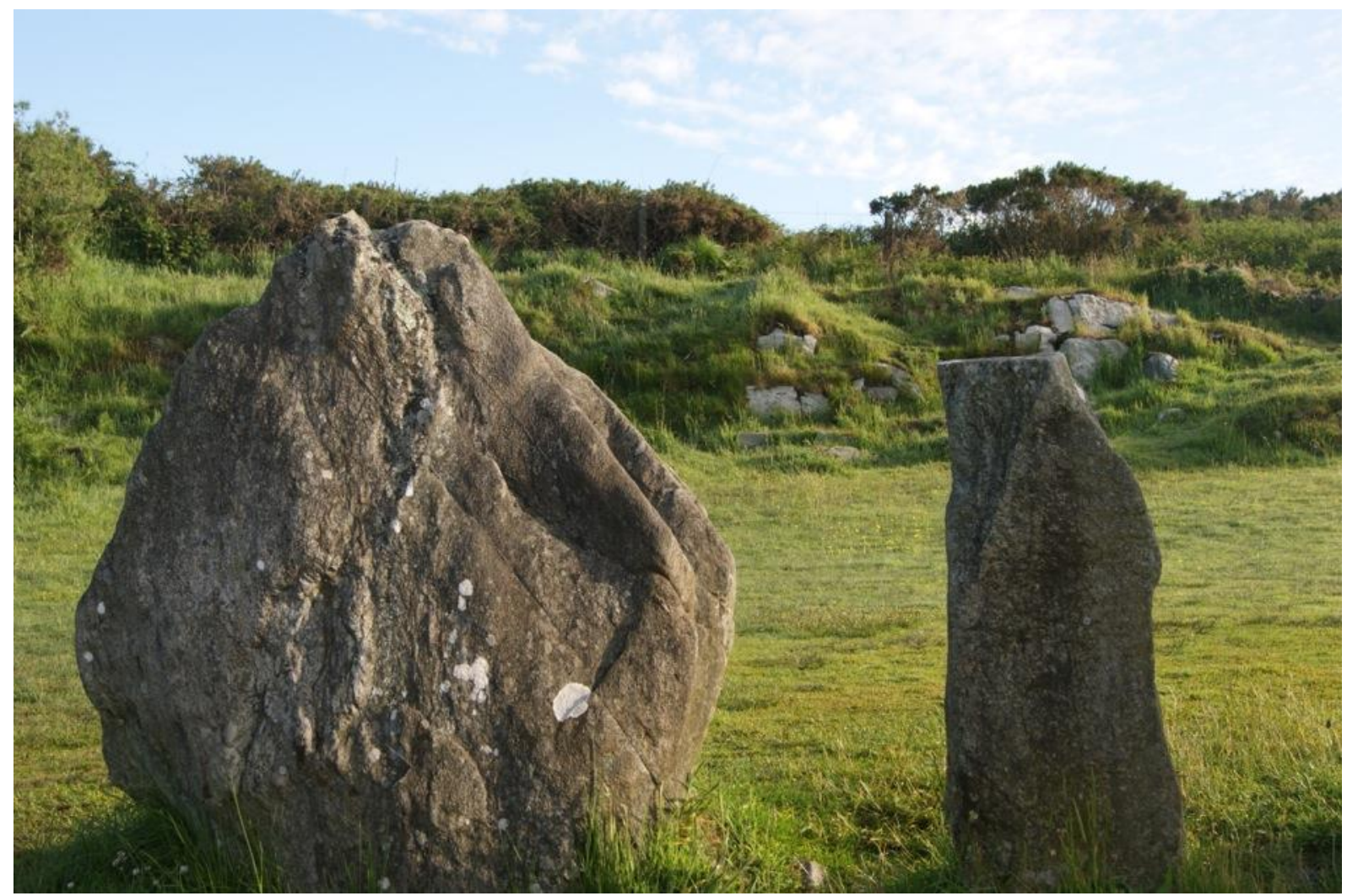

Figure 9. Stones 14 and 15. The pillar stone is offset with respect to the regular perimeter of the circle, contrast with the plan in Figure 3. By deliberately choosing shaped rocks, improved with sculptural help, they illustrate female and male imagery. Photographed early morning 25 June 2012 by the author.

\subsection{The pillar megalith}

Adjacent to the lozenge megalith is the short narrow Stone 15 (Figure 9). It is $1.10 \mathrm{~m}$ high, $48 \mathrm{~cm}$ wide and $25 \mathrm{~cm}$ thick. Total weight is no more than $400 \mathrm{~kg}$. Fahy (1959: 5) writes that it "differs from all surviving stones in the circle and though no tool marks are visible on its surface or angles its rather phallic outline can hardly have been an accidental occurrence". Fahy (1959: 20) further writes that Stone 15 "seems to have been fashioned into its present shape in antiquity".

In contrast to its neighbours Stone 15 is oddly located in a forward position relative to Stones 14 and 16. Compare by referring to the plan in Figure 3. This ensured that at the equinoxes (as explained below) the rising sun would shine through the gap between Stones 16 and 17 and illuminate the eastern side of Stone 15, throwing its shadow on to Lozenge Stone 14.

\section{Results}

Firstly, it is demonstrated how at the five agricultural festival dates of the summer months from the spring equinox to the autumn equinox all the stones from Stone 1 to Stone 5 at sunrise cast shadows in turn upon the recumbent stone (Sections 4.1 to 4.3).

This is followed by considering the run of five agricultural festival dates of the winter period from autumn equinox to spring equinox including the winter solstice in which three different stones throw sunrise shadows upon the lozenge megalith (Sections 4.4 to 4.7).

It is then demonstrated how at Knowth and Newgrange shadows are similarly cast at the relevant seasons upon appropriate stones (Sections 4.8 to 4.9). 


\subsection{Drombeg light and shade effects at the summer solstice sunrise: Showing how the shadow of Portal Stone 1 is cast upon the symbols on the recumbent stone}

Significantly, portal Stone 1 and the central part of the recumbent megalith (Stone 9) are aligned on midsummer sunrise (Figures 10 and 11), immediately after which the sun casts a weak shadow of the portal stone upon the recumbent. Note that there is a time delay approaching seven minutes as regards the time of the local summer solstice sunrise due to the roof of a single-storey twentieth-century house and vegetation in that direction.

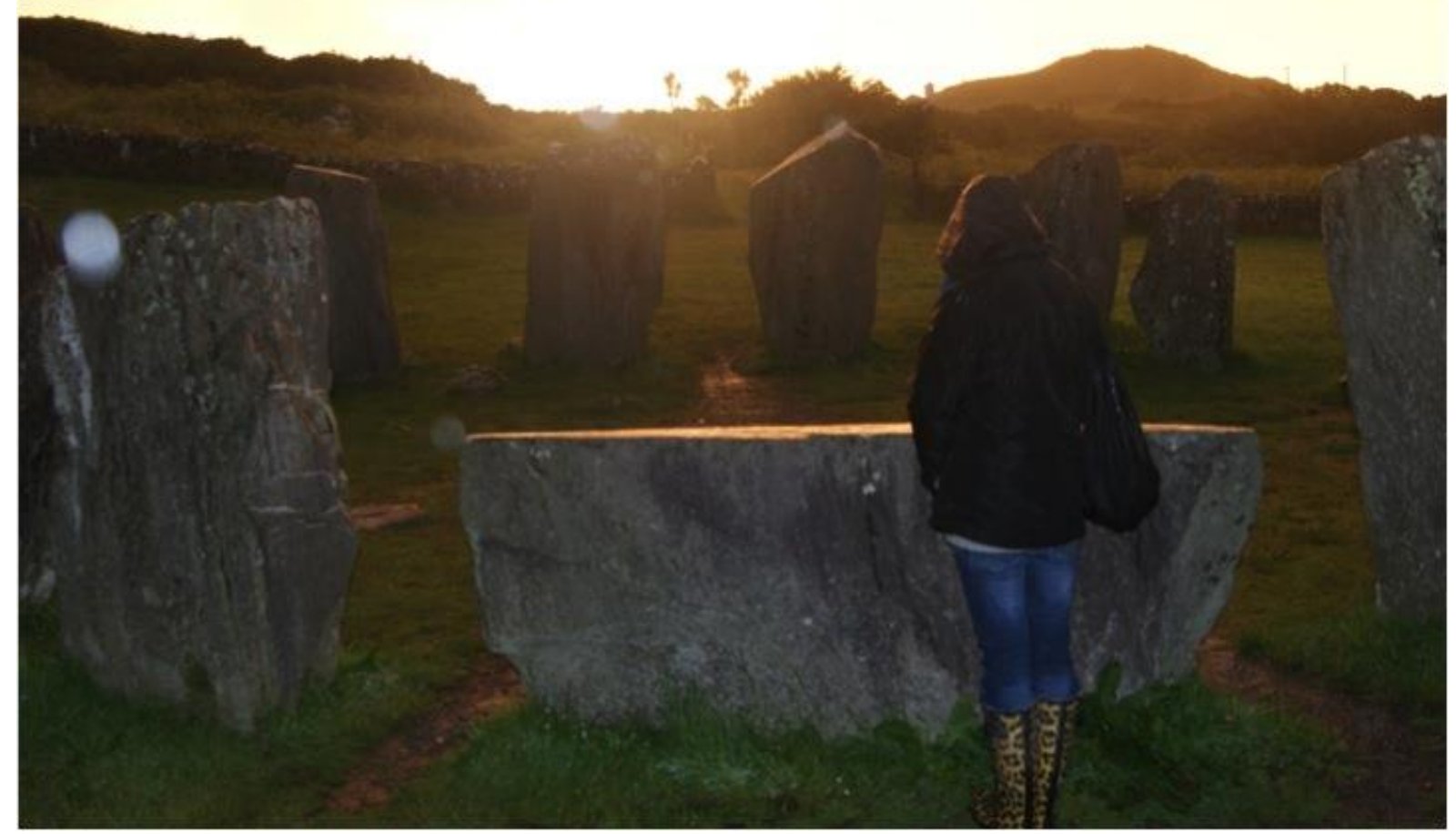

Figure 10. This shows the disposition of the standing stones as seen from the recumbent stone. The time was a few minutes before sunrise on 19 June 2012 with steady rain falling. Author's photograph.

Figures 12 and 13 show the subsequent progress of the shadow as it gains strength while moving along the recumbent stone.

The last photograph (Figure 14) shows the position of the shadow still later when the carvings are illuminated.

In the absence of cloud the sun first gleams over the house roof on the horizon at about 0557. Also, compared with modern times, because of the precession of the equinoxes, the sun would have risen in prehistoric times one degree (equivalent to two solar diameters) farther north along the horizon - and the shadow just after sunrise would have covered still more of the recumbent stone than it does today.

The shadow of the portal stone moves northwards as the sun moves south. The illuminated area of the recumbent stone advances too, eventually reaching the carvings (Figure 14). This last photograph and the next (Figure 15) taken at 0615 show the carvings fully illuminated and the shadow of portal Stone 1 nearer to leaving the recumbent stone.

The plans in Figure 16 explain the situation for 21 June. The days three or four days earlier or later are scarcely different. 


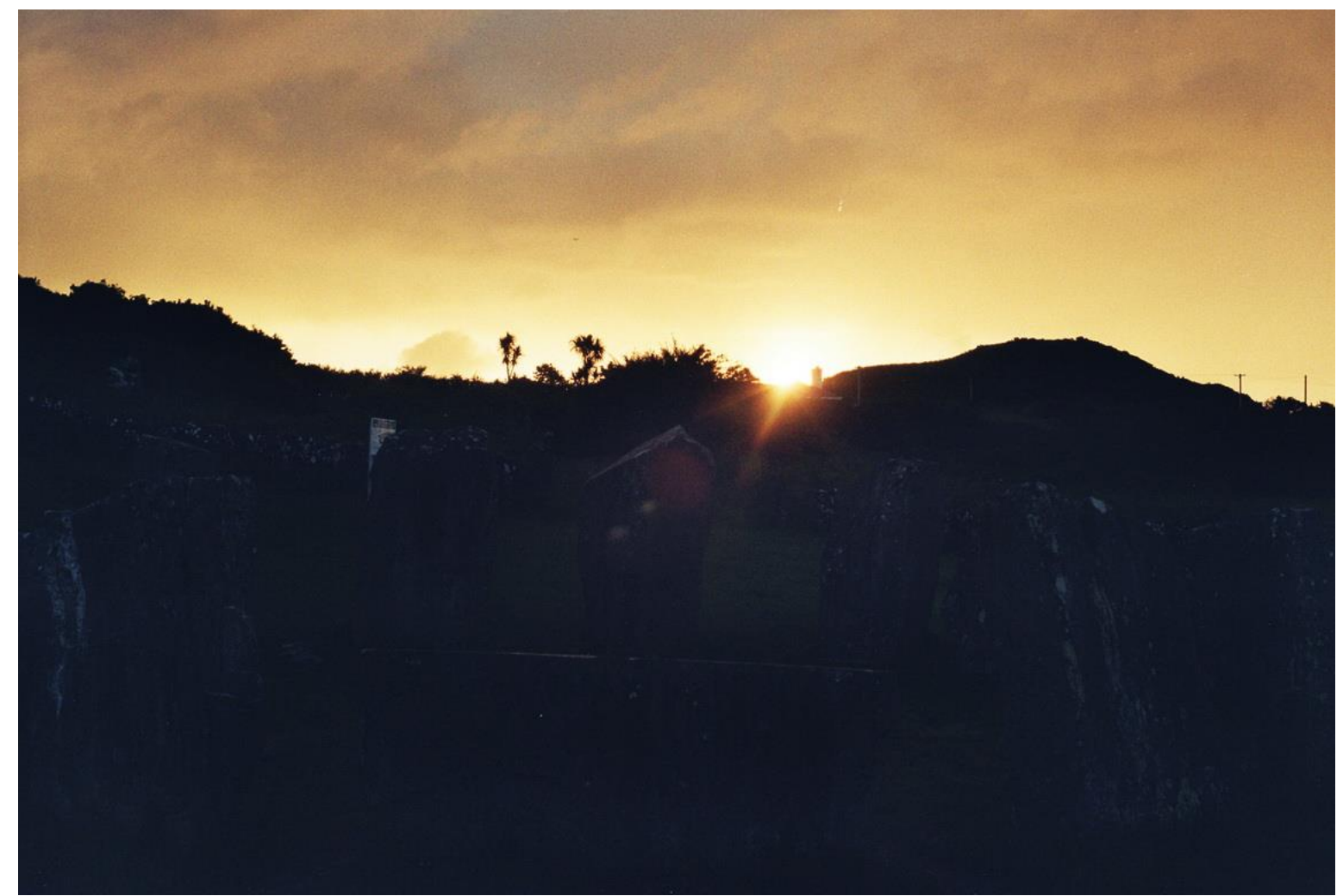

Figure 11. This shows where the sun rises at the summer solstice as seen from the recumbent stone. Compare with the stone positions in Figure 10. The emerging sun aligns with the south-eastern edge of portal Stone 1 and a point to the south of the middle of the recumbent stone. In contrast with the prehistoric situation, the sun's arrival is delayed by a few minutes because of an intervening house roof and vegetation. On 19 June 2012 the top of the orb began to appear at about 0557 Irish Summer Time but sunlight was then blocked as rain clouds reached the horizon. Author's photograph.

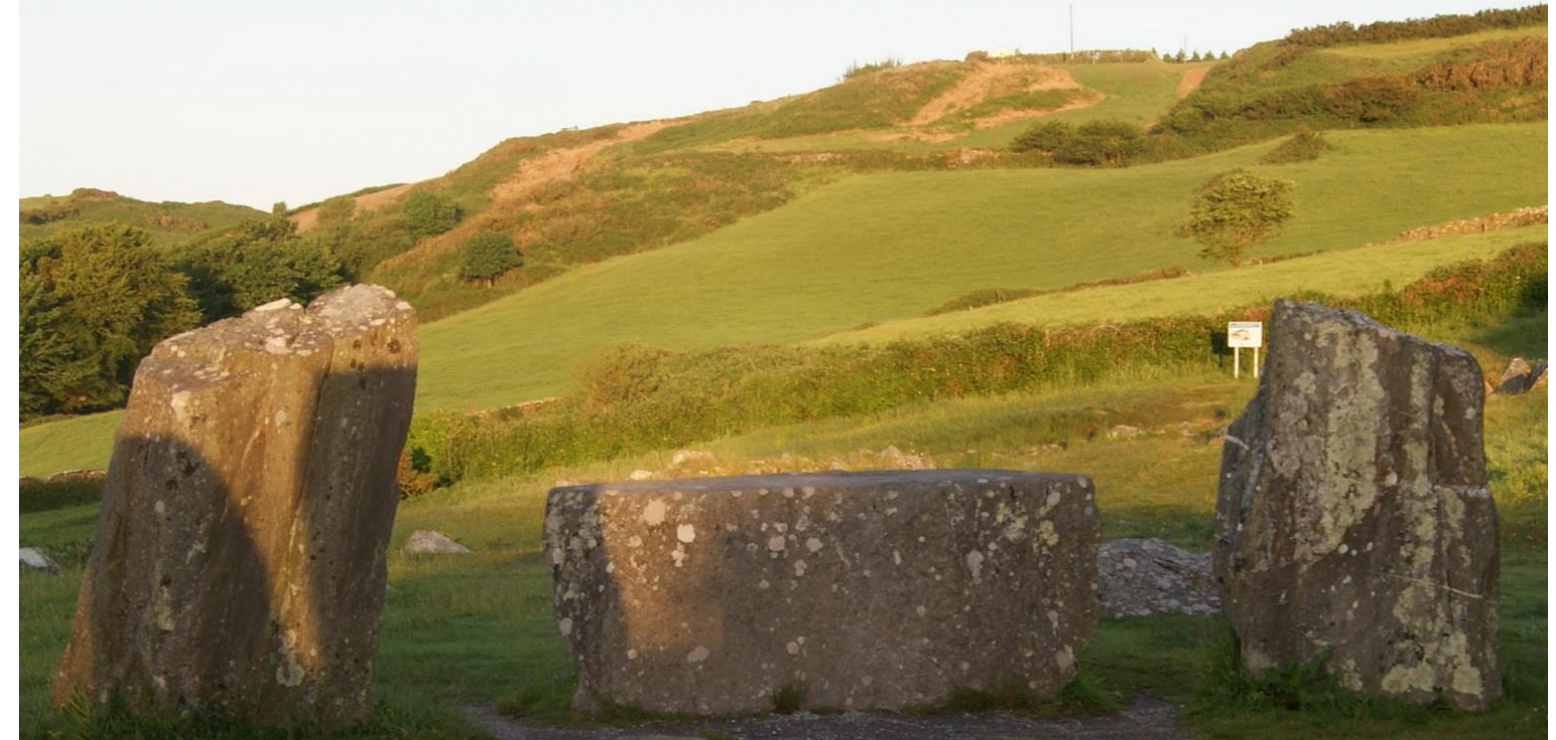

Figure 12. Photograph looking south-west. On 17 June 2013 distant cloud in the north-east initially blocked the local sunrise, but a little later at about 0600 the sun appeared and the shadow of Portal Stone 1 lay, as shown, across the right half (i.e. the north-western part) of the recumbent Stone 9 (unfortunately a small spurious shadow is present too. Contrast with Figure 13) while the shadow of Stone 2 straddles Stones 8 and 9. Note that the carvings on the recumbent stone remain engulfed in the shade of the portal stone. All the while, the sunlit section between the shadows of Stones 1 and 2 shifts steadily northwards (i.e. to the right ). Author's photograph. 


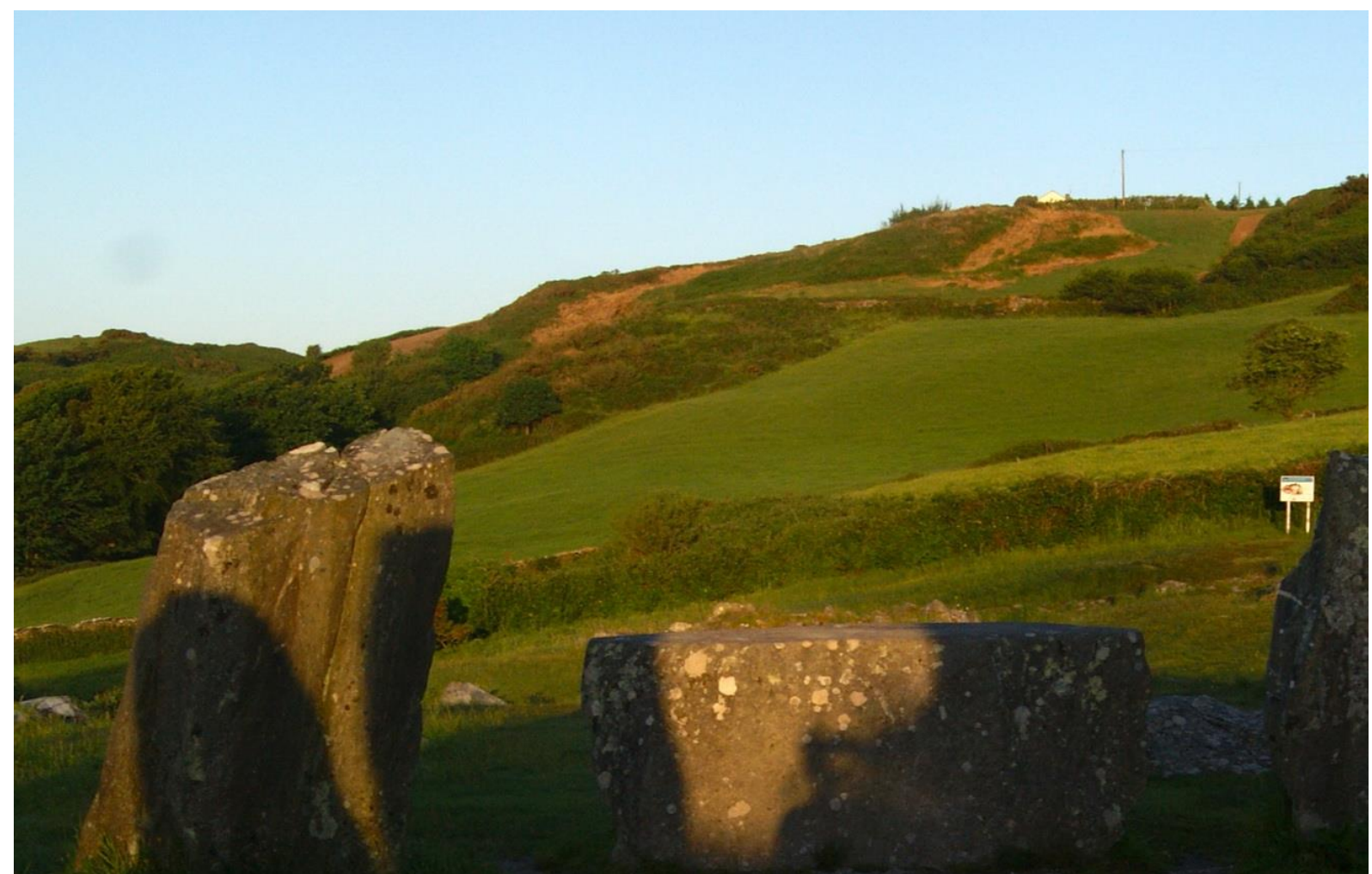

Figure 13. A little later the shadow of the portal stone has moved farther northwards allowing sunlight to start illuminating the carvings on the recumbent stone. (The spurious extra shadow on the latter is still a nuisance although it is not detrimental to the explanation). Author's photograph.

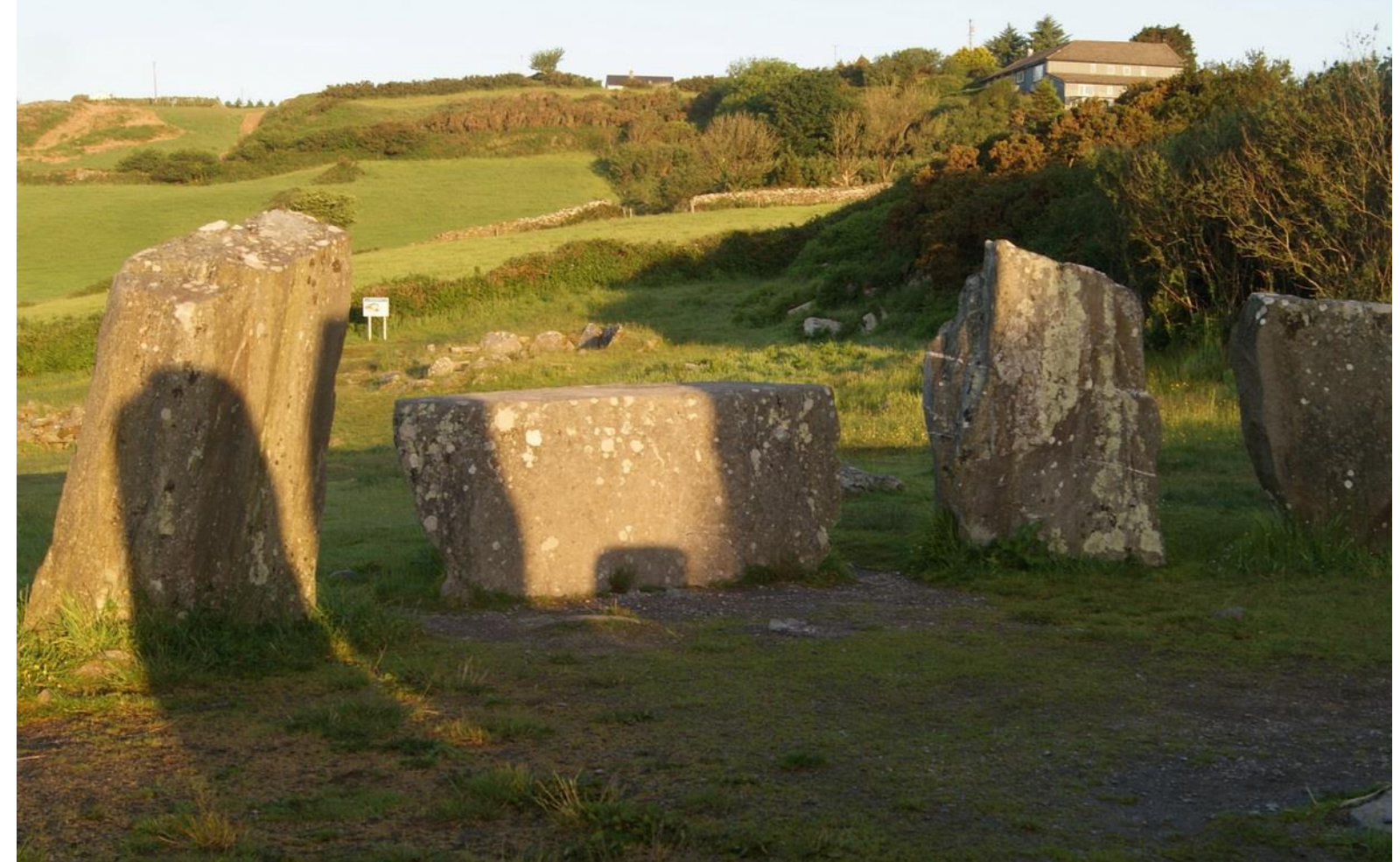

Figure 14. A few minutes later the pecked carvings are completely illuminated - and the sun is brighter and the shadows sharper. 


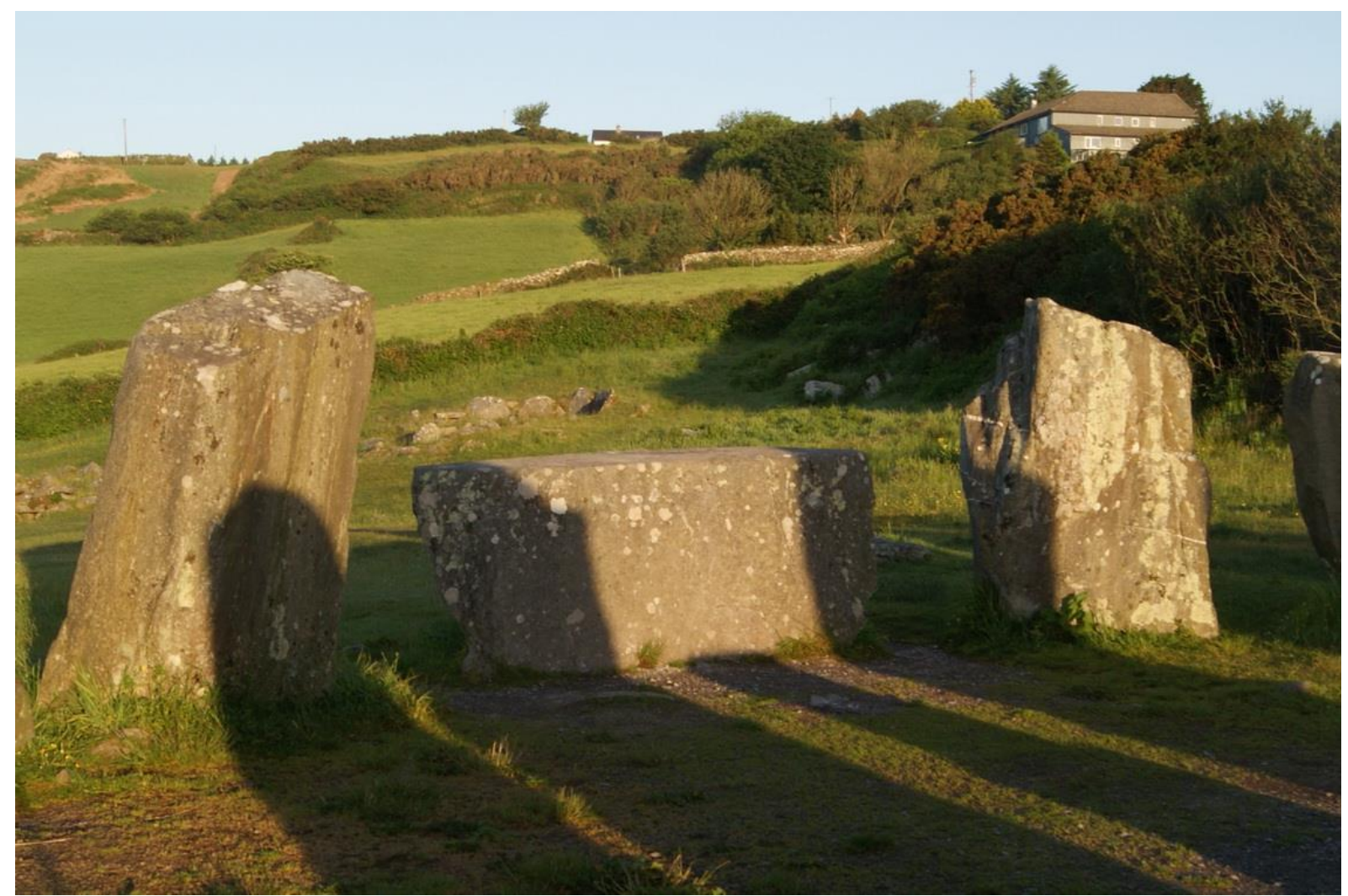

Figure 15. This later picture was taken by the author at 0615.
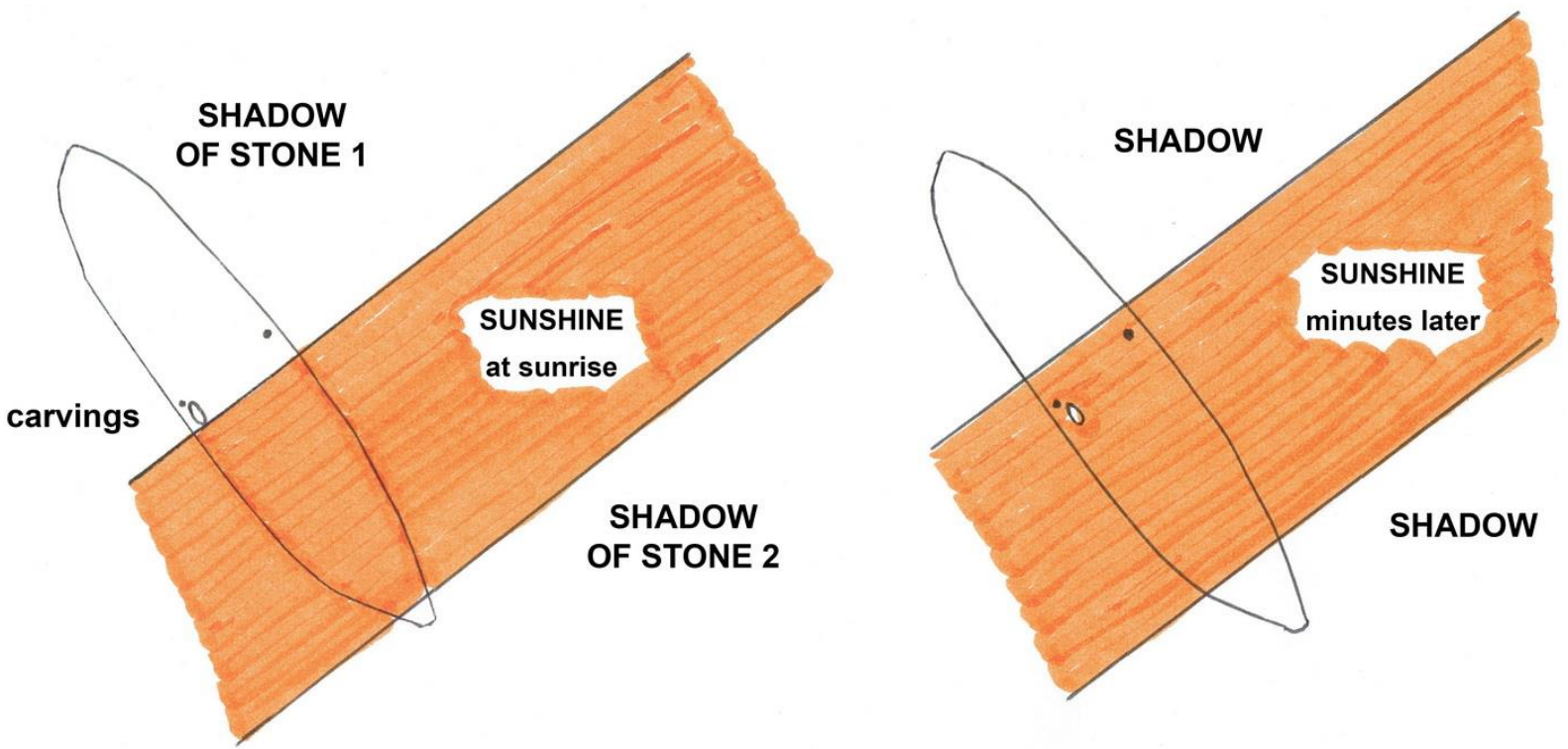

Figure 16. Initially, just after sunrise about a third of the recumbent stone is in sunshine (as in the photograph of Figure 12). The carvings are then wholly in the shadow of the portal stone. Gradually, the sunshine nears the carvings as indicated in the first plan (at left). A little later (second plan) the golden light of the sun reaches and illuminates the carvings. In these plans shadows are shown white.

A possibility that is discussed later (in Section 5) is that this may represent a calendrical fertility union between a male stone and female recumbent. This may have been interpreted as a union between Sun and Earth (the latter represented by the recumbent stone and its principal carving) implying a 'marriage' between Sky Father and Earth Mother, in the sense of the hieros gamos, so long glorified by the classical Greeks (Burkert 1985). No references to an 
Irish or British Neolithic or Bronze Age hieros gamos can be cited because these early communities were not literate and left nothing in writing, but the myth is known elsewhere in the world from later ages and up to modern times - including, for instance, tribal stories recounted to anthropologists in India (Das 2014: 31-34) and North America (Krupp 1997; Bender 2017).

\subsection{Drombeg sunrise light and shade effects at the equinoxes relative to the recumbent stone: Showing how Stones 4 and 5 jointly cast shadows upon it.}

Figure 17 shows Stones 4 and 5 viewed from near the circle centre, and Figure 18 the same stones when observed from the recumbent Stone 9. The angled view in Figure 18 was deliberately arranged by the planners, and provides a lithic V-notch and a vertical crevice in line with the sun rising at or close to the equinoxes.

Figure 19 shows the sun rising through the V-notch.

Figure 20 is a photograph taken a few minutes later when the sun is brighter, having cleared the trees. The vertical shaft of light is still upon the recumbent Stone 9, while the light passing the V-notch is visible upon the upper surface of the flat stone close to the carvings. Without the delay caused by trees, the main carving on the recumbent stone would have commenced wholly in shadow before becoming illuminated by the light of the sun.

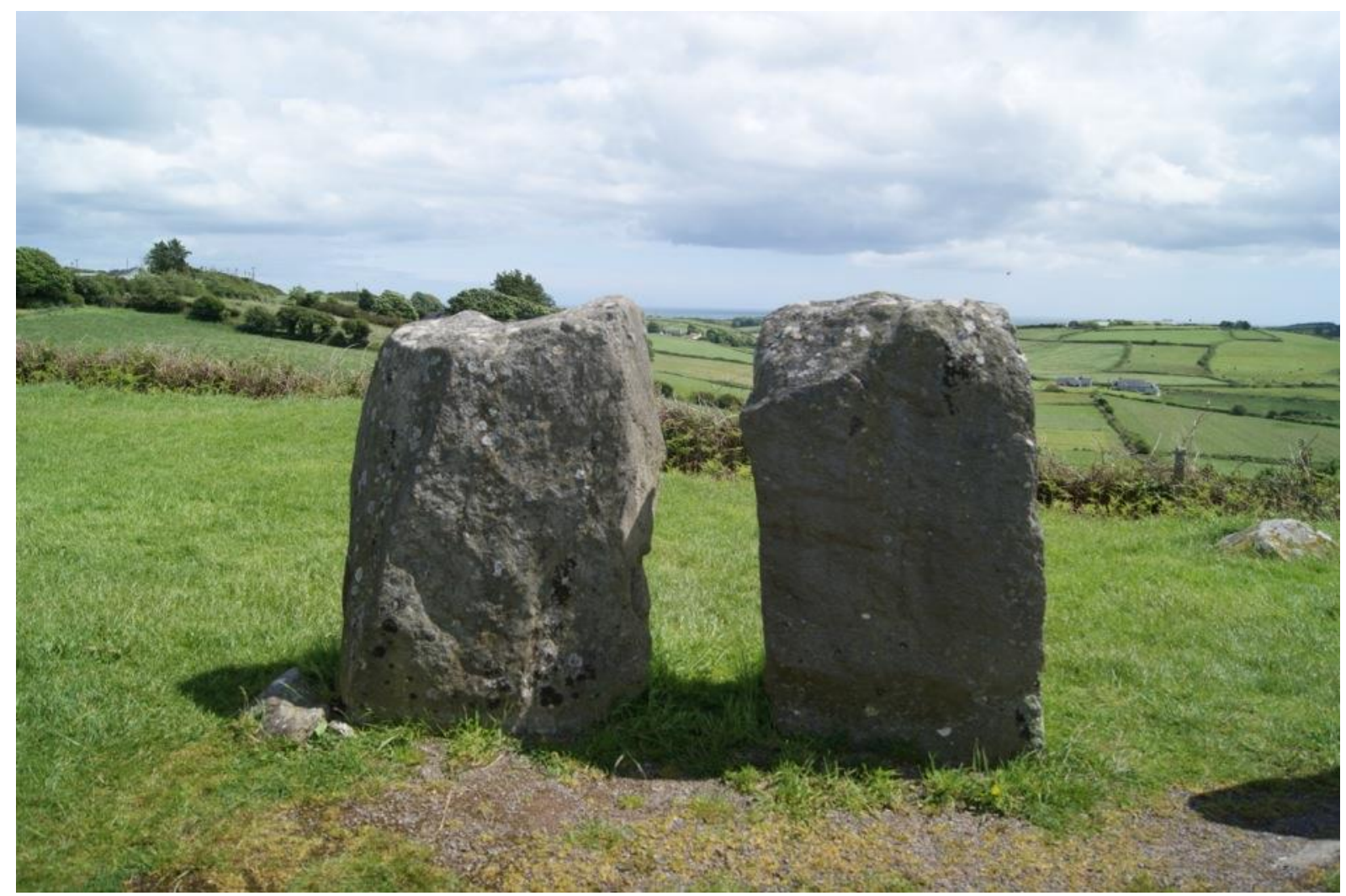

Figure 17. Stones 4 and 5 as viewed from near the circle centre. Author's photograph. 


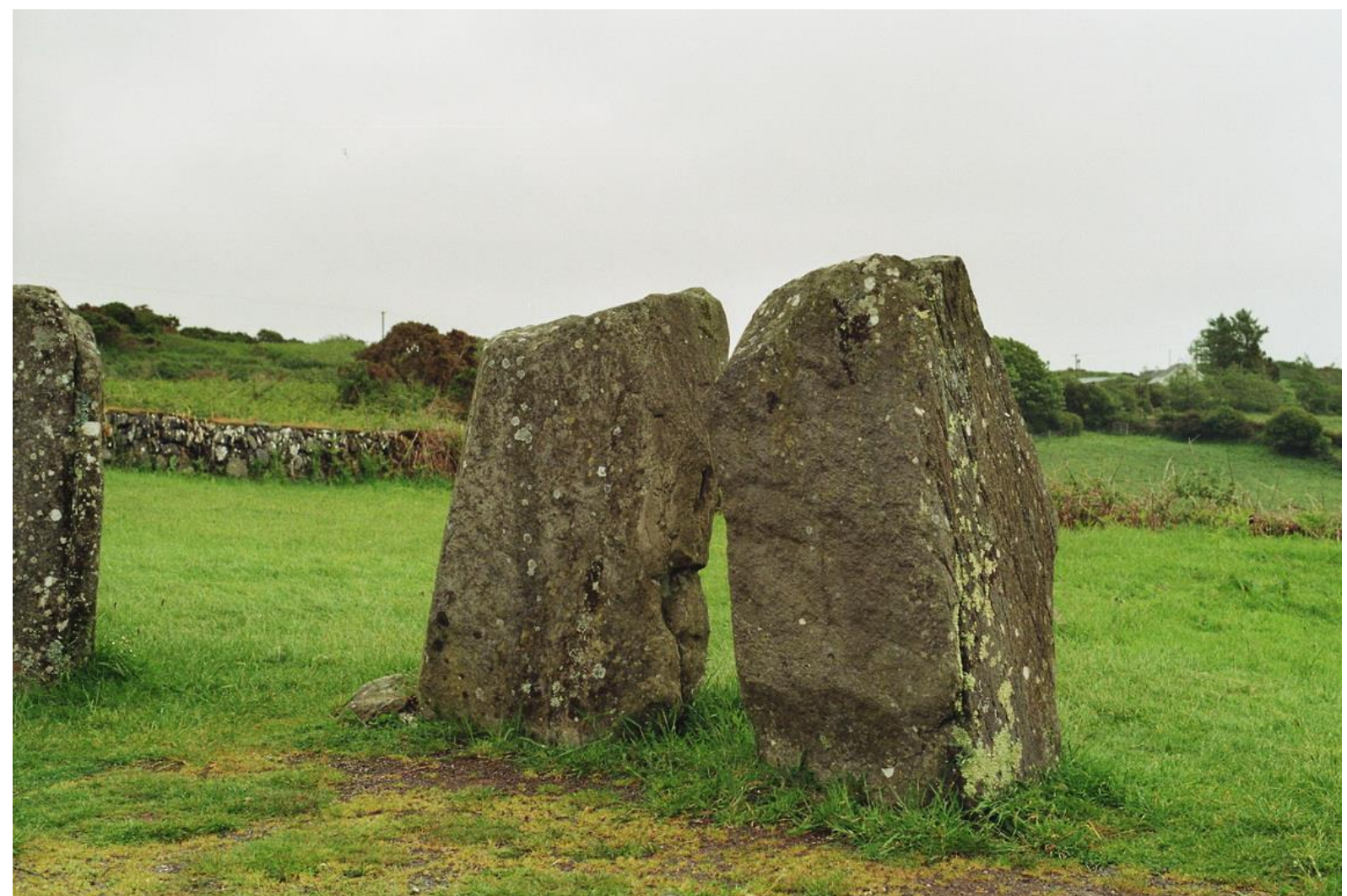

Figure 18. The angled view of Stones 4 and 5 when seen from the recumbent Stone 9. Notice the V-notch and vertical gap between the stones through which sunlight passes at the equinoctial sunrises. Author's photograph.

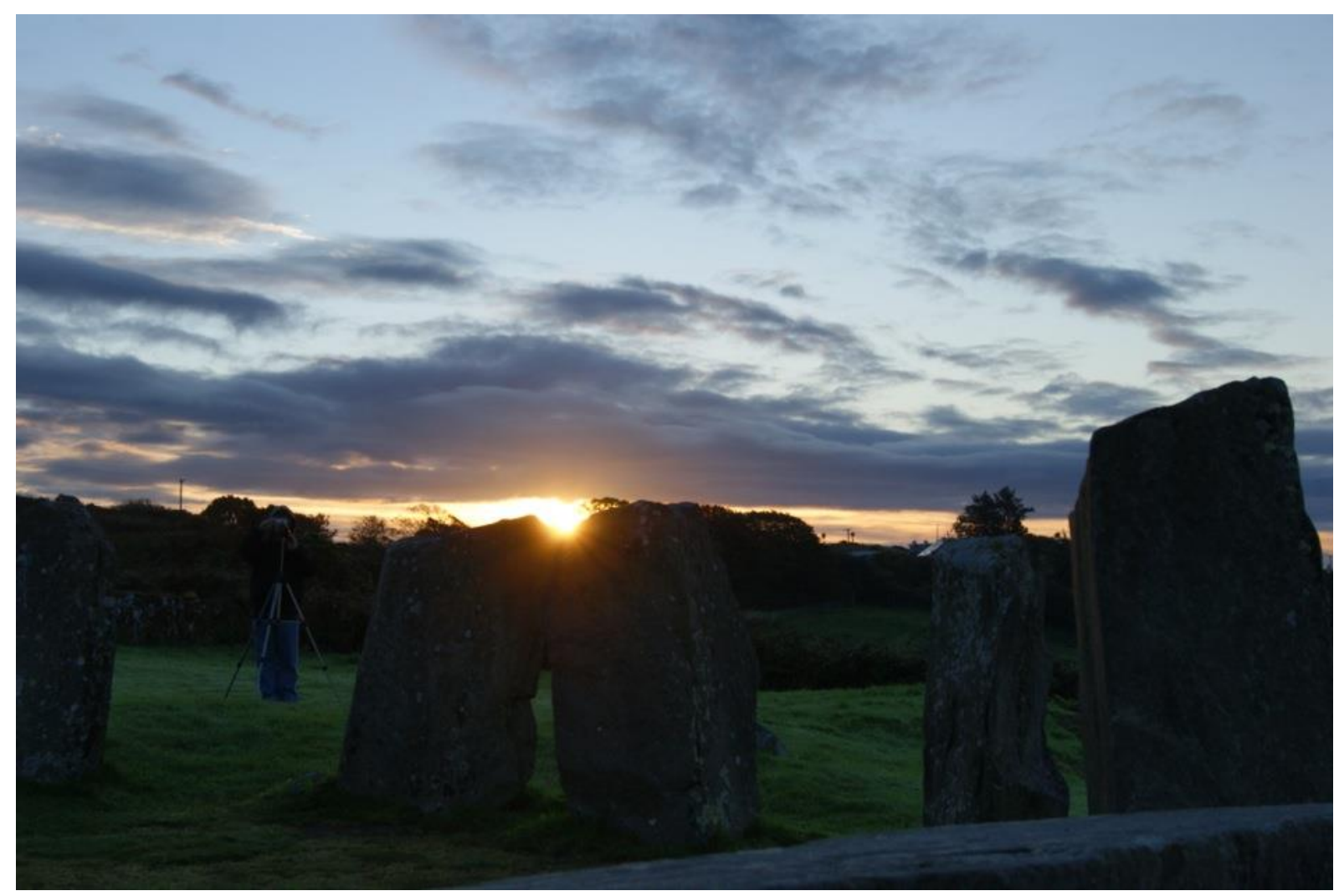

Figure 19. Autumn equinox, 21 September 2012: The sun is seen in the lithic V-notch, rising from behind trees on the horizon in the east. At the same time the sun is shining through the narrow vertical space between these stones. Author's photograph. 


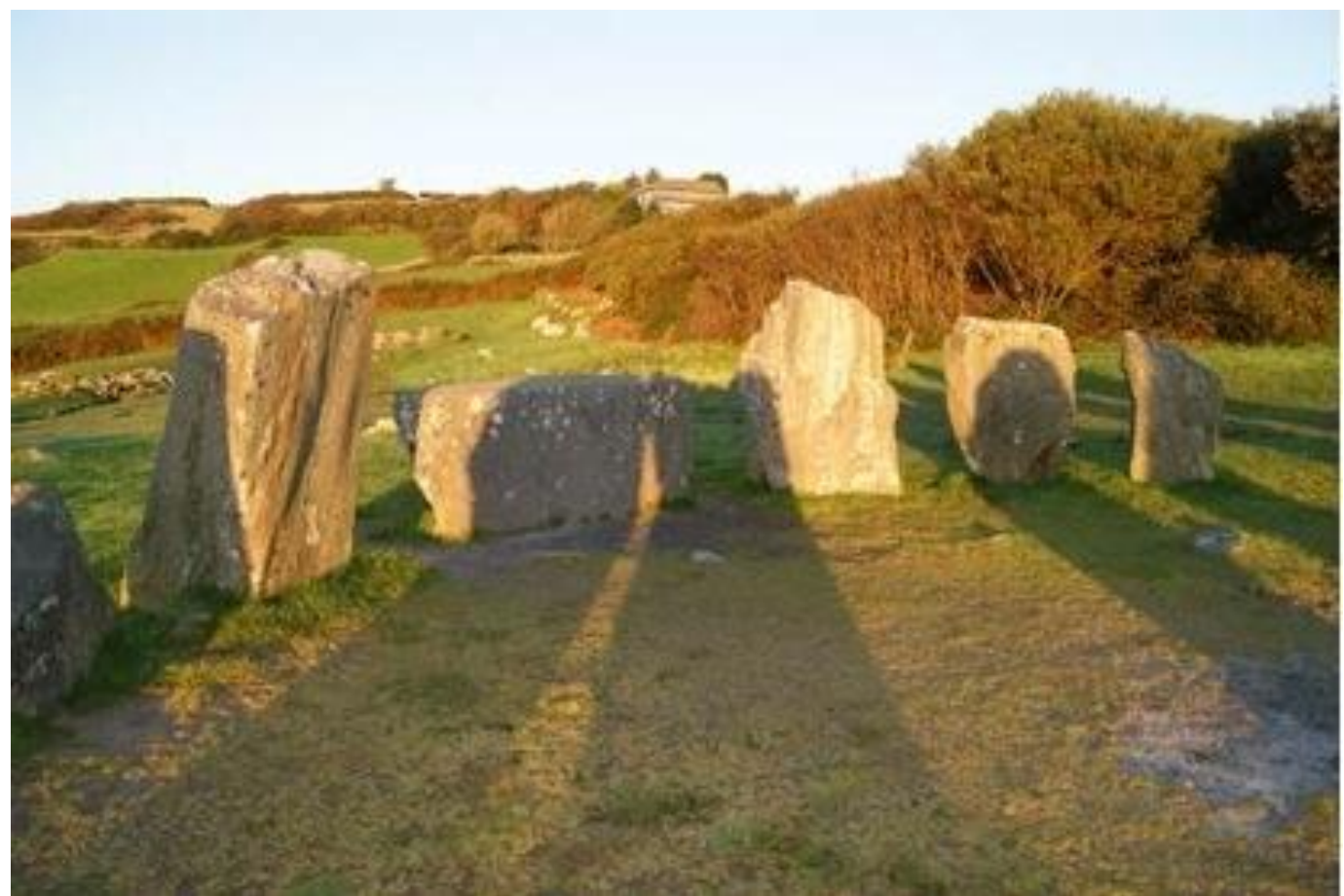

Figure 20. Looking west a few minutes after sunrise, the narrow shaft of light from between Stones 4 and 5 falls upon the recumbent stone. Author's photograph.

\subsection{Drombeg sunrise light and shade effects at the May and August festivals of the agricultural year: Showing how Stones 2 and 3 cast shadows upon the recumbent stone}

The date on the reconstructed Neolithic-Bronze Age calendar for the end of spring and the start of summer is 6 May (Section 2.2 of this paper). It is Day 137, midway between the spring equinox (22 March, Day 92) and midsummer solstice (21 June, Day 183).

Solar azimuths are the same for 6 August as for 6 May, so it is the same for the Beltane festivities (i.e. prehistoric May Day) as for prehistoric Lughnasadh on 6 August.

The principle behind the positioning of Stones 2 and 3 is shown by the plans in Figures 3 and 21, and explains how at sunrise on the indicated dates the principal carving on the recumbent stone begins in shadow (Figure 22) from whose darkness it is released a few minutes later (Figure 23). Note that in prehistoric times, because of the precession of the equinoxes, the sun would have risen rather further north so the shadow of Stone 2 would have fallen on to Stone 9 a little further south. 

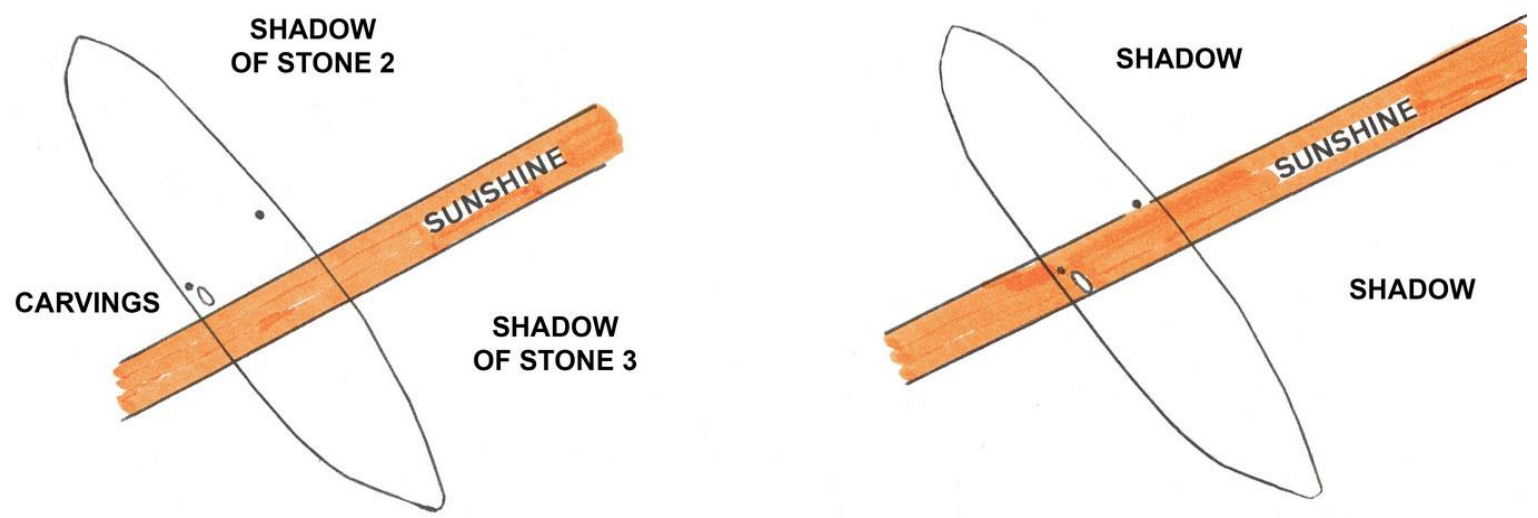

Figure 21. (Left) At Beltane sunrise on 6 May, as on 6 August, the shadow of Stone 2 crucially covers the carvings on the recumbent stone (compare with the plan in Figure 3). (Right) A few minutes later, a golden shaft of light from the moving sun illuminates the carvings. In these plans shadows are shown white.

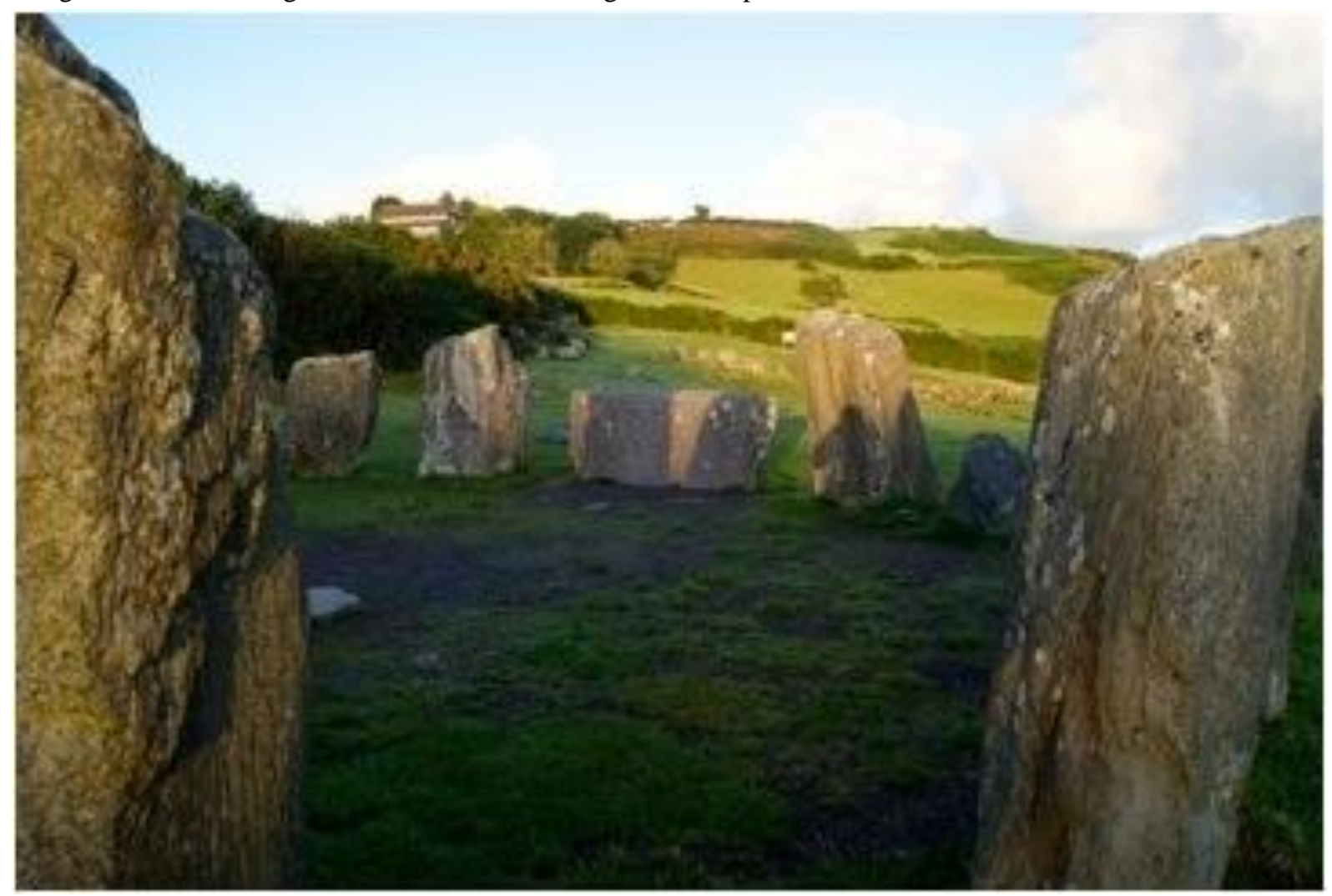

Figure 22. The shadow of Stone 2 initially engulfed the carvings on the right half of Stone 9 but in moving away to the right it began to allow the sunlight to arrive. The time was shortly after sunrise on 3 August 2013. Author's photograph. 


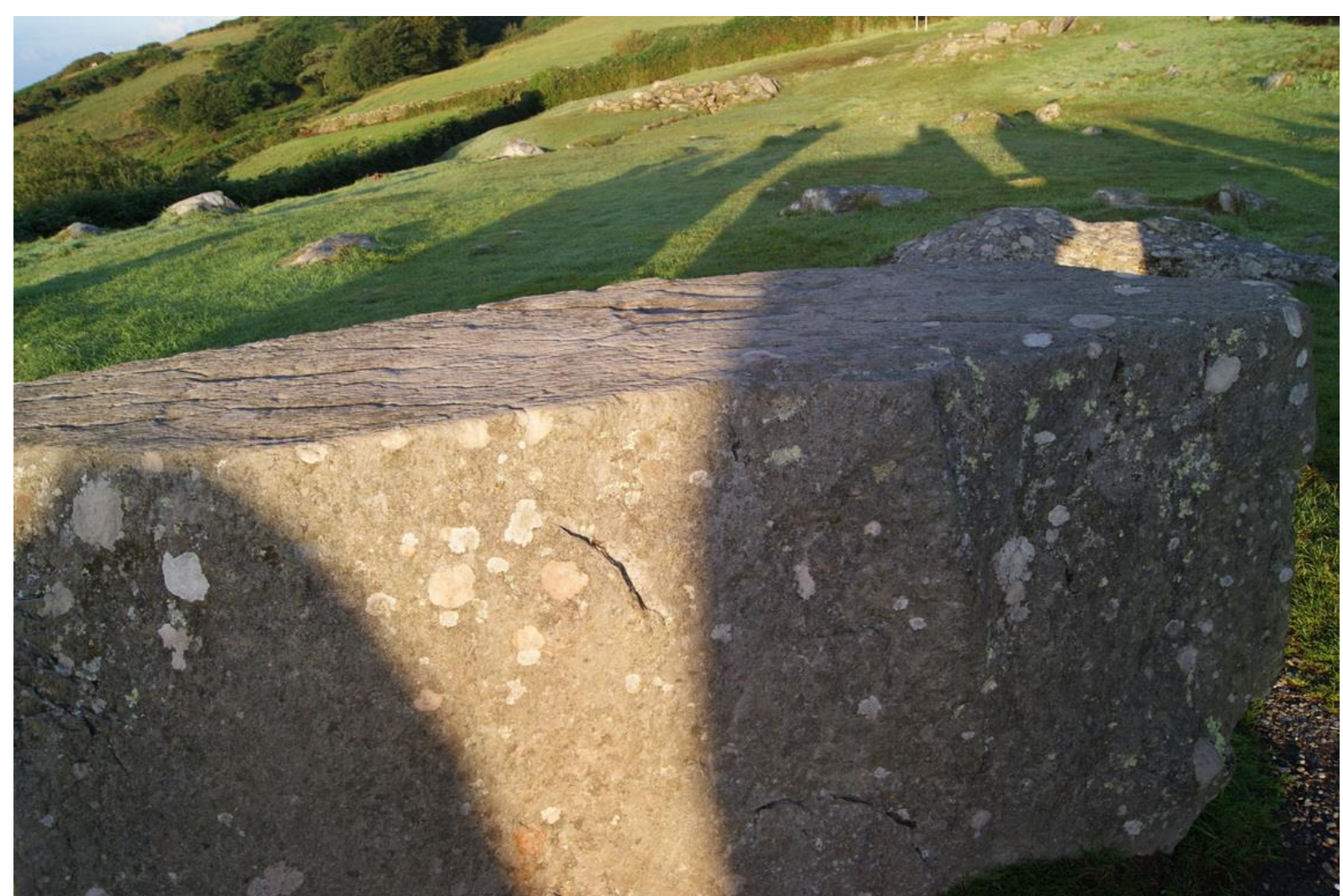

Figure 23. This photograph by the author shows that at 0649 the Stone 2 shadow (at right of picture) has almost cleared the feminine symbol on Stone 9 after which the latter is fully illuminated by the sun.

Figure 23, taken on 3 August, indicates how much the shadow has moved in the several minutes since sunrise. Figures 23 and 24 show the top surface of the recumbent stone at the moment when the shadow is clearing the northern end of the longitudinal carving at 0649. 


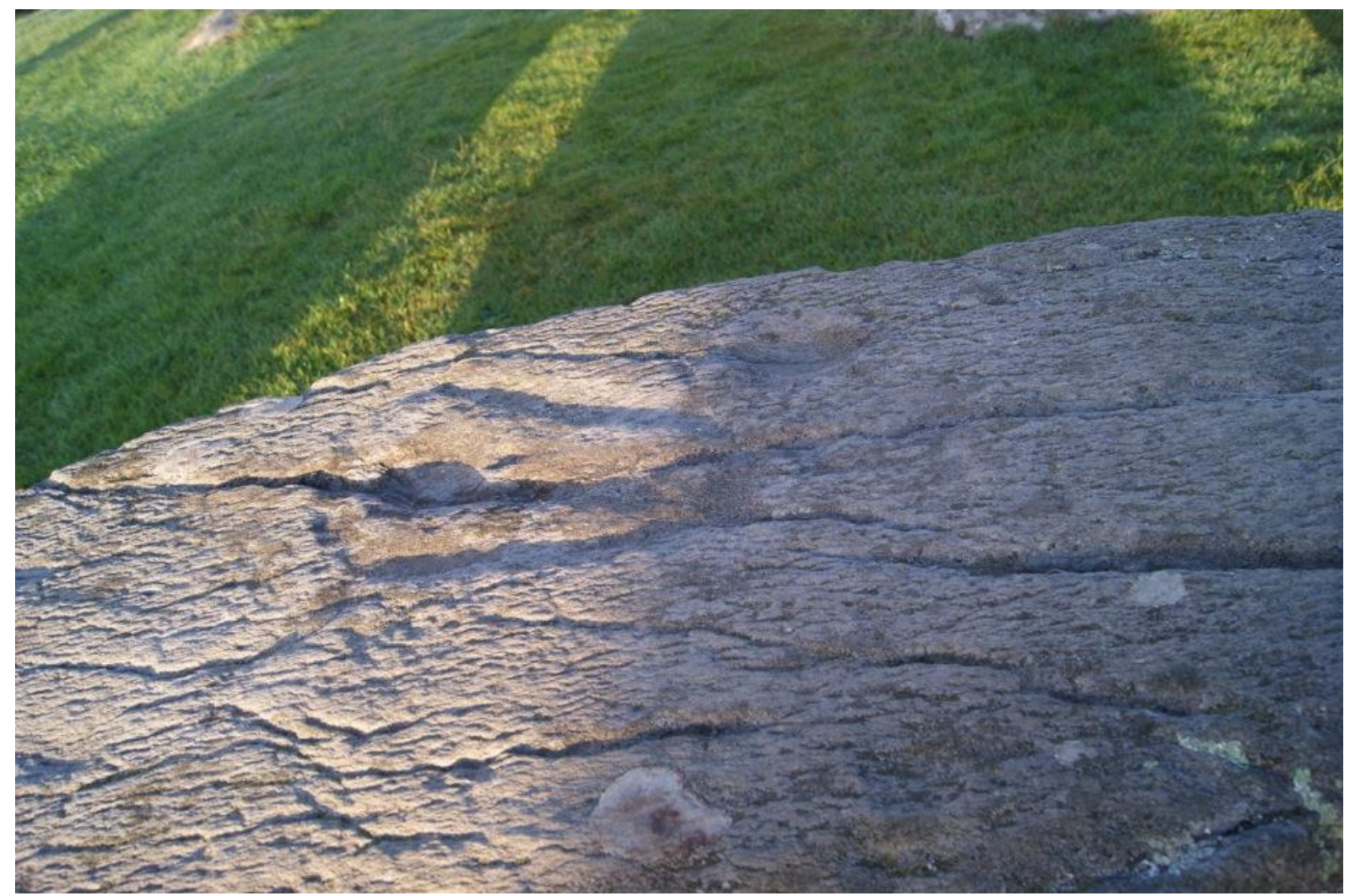

Figure 24. Another photograph of the same image on Stone 9, also taken at 0649. Author's photograph.

\subsection{Drombeg sunrise light and shade effects at the equinoxes relative to the lozenge Stone 14: Showing how the pillar Stone 15 casts a shadow upon the former.}

At each equinox two displays take place simultaneously involving iconic union by shadow and then light. One was described in Section 4.2 (namely, when Stones 4 and 5 jointly cast shadows upon the recumbent stone).

The second is a pairing that repeats, via artistic shadow imagery, the linking of potentially male and female stones in a manner that emphasizes the proposed gender interpretation. This is again a result of deliberate lithic selection as explained in Sections 3.3 and 3.4 following the comments about Drombeg initiated by the excavator Fahy (1959).

At the September equinox (the autumn third quarter day, 21 September) the union heralds the importance of the lozenge stone for the forthcoming winter six months of the year. At the March equinox (the spring first quarter day, 22 March) the union serves to terminate the winter half of the year.

It was explained in Section 2.2 that 21 September is Day 275, being midway between the summer solstice Day 183 (21 June) and the winter solstice Day 1. Day 92 is 22 March because it is midway between the winter solstice Day 1 and the summer solstice Day 183.

Compare the photographs of Figure 25 with the photograph of the same stones (14 and $15)$ in Figure 9. This shadow effect happens only at the equinoxes. It arises from the special positioning of Stones 14,15, 16 and 17 (refer to the plan in Figure 3) by which the builders contrived to allow the passage of sunlight through a narrow gap created between Stones 16 and 17, to fall upon the offset pillar stone whose shadow unites it with the centre of the lozenge stone. Fahy $(1959,20-21)$ suspected that the shapes of these stones may indicate a fertility cult in some manner (Section 3.3), and here one can possibly see why. 

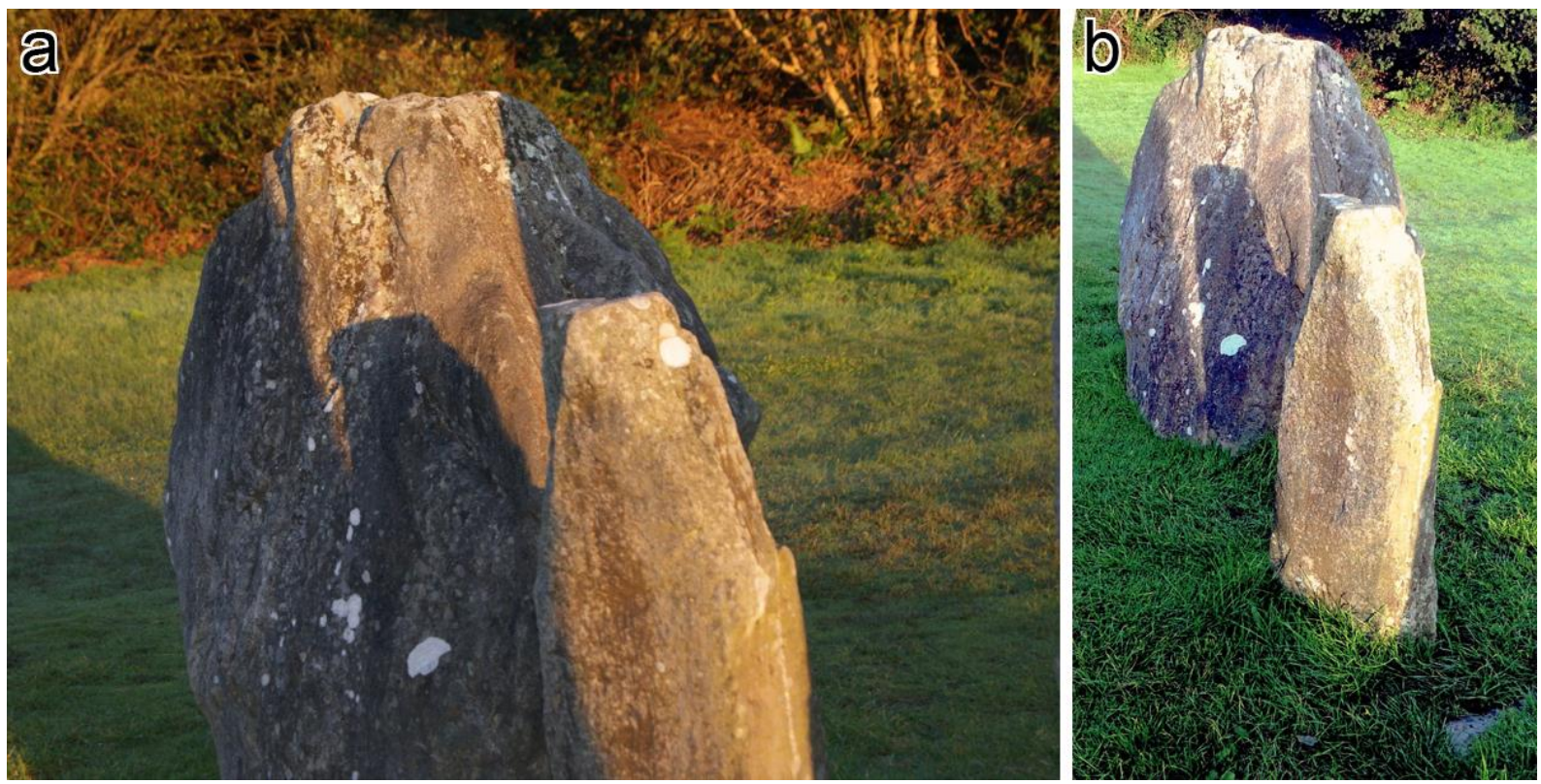

Figure 25. a. Medial union of the sunlit pillar Stone 15 with the lozenge Stone 14 by shadow at sunrise on 21 September 2012. The light of the rising sun passes through the prepared lithic gap between Stones 16 and 17 , to reach the offset pillar stone in order that its shadow meets the centre of the lozenge stone. b. Similarly.

Furthermore, as this shadow moves away, the bigger shadow of the tall straight-sided portal Stone 17 replaces it in a central position on the lozenge stone. This portal stone has the ithyphallic carving on it (Figure 8).

\subsection{Drombeg sunrise light and shade effects at the February and November festivals of the agricultural year: Showing how Stones 2 and 3 cast shadows upon the lozenge Stone 14}

On 5 November 2012 - Day 320 which is midway between autumn equinox (Day 275, 21 September) and Day 1 (the winter solstice) of the 365-day calendar - sunrise photographs were taken. Figure 26 was taken seven minutes after sunrise when the lozenge stone was still almost completely covered by the shadow of Stone 2 . A few minutes earlier (as per Figure 27) the lozenge had been completely in shadow.

It would be the same for the Imbolc festival, Day 47, which we know as 5 February - the date midway between the winter solstice (Day 1) and the first quarter day, Day 92 on 22 March.

\subsection{Drombeg sunrise action at the winter solstice involving shadows and the lozenge stone}

At the winter solstice the sun rises over the sea instead of from behind hills which it does for the seven other festival dates of the year previously discussed.

As regards the action of sun and shadow at the great lozenge stone, prehistoric circumstances differed from the current situation because a major stone is missing from the Drombeg monument. Because this stone was described and measured by Franklin (1903, 2324), we call it the Franklin Stone. Six years later Somerville (1909) found it to be missing. In 2012 the present author sought to trace it, and found a likely stone only 500 metres away at Drombeg House where it had stood for over a century (Figure 28). Franklin records it, explaining that in the stone circle, "there is a central stone, rather round, 3 feet high and 22 inches wide". These measurements accord with the stone that the author found. 


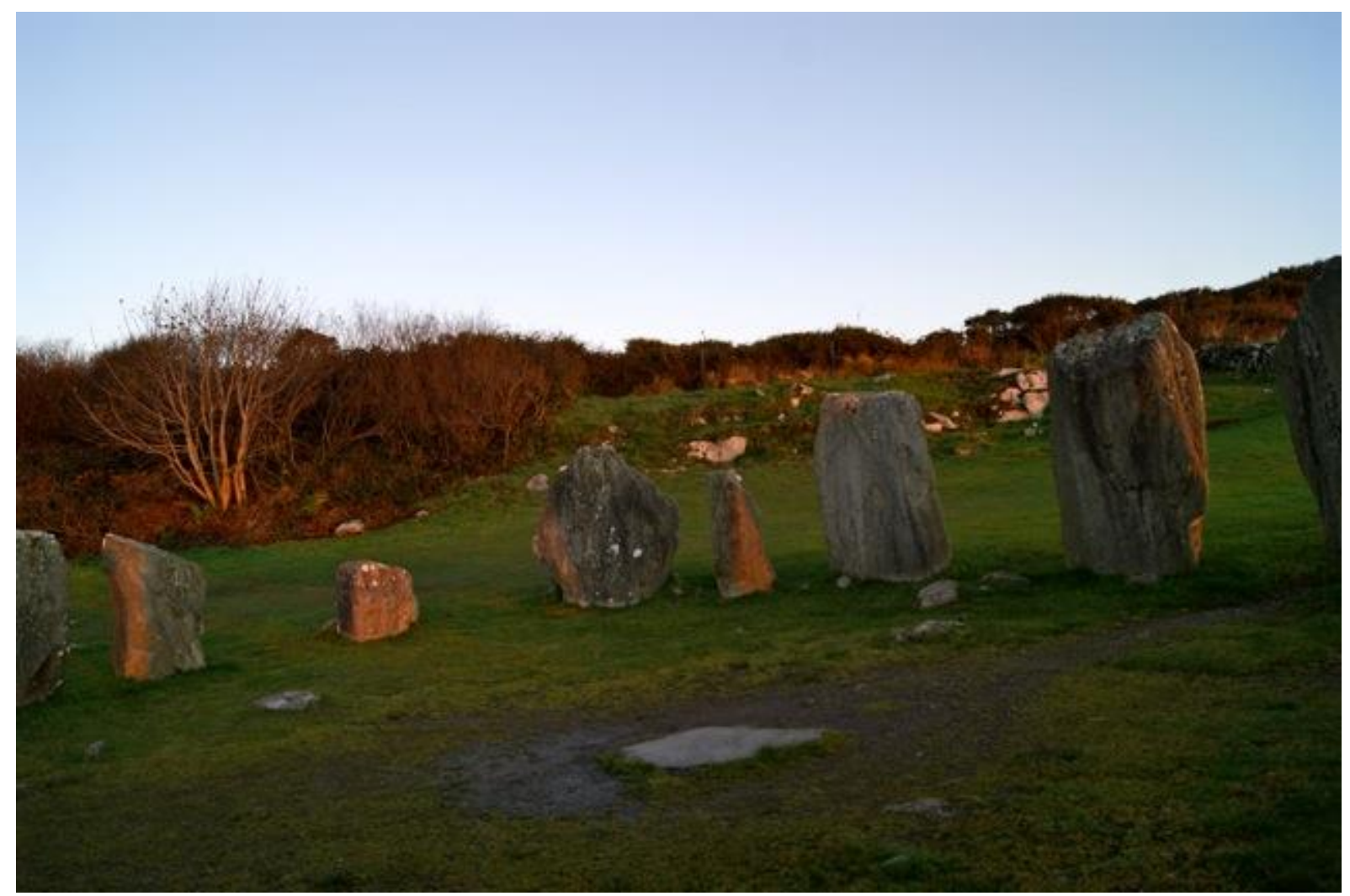

Figure 26. 5 November 2012. This photograph of the lozenge stone was taken by the author standing between Stones 5 and 6 at 0743 , seven minutes after sunrise. It is the shadow of Stone 2 that covers the lozenge stone.

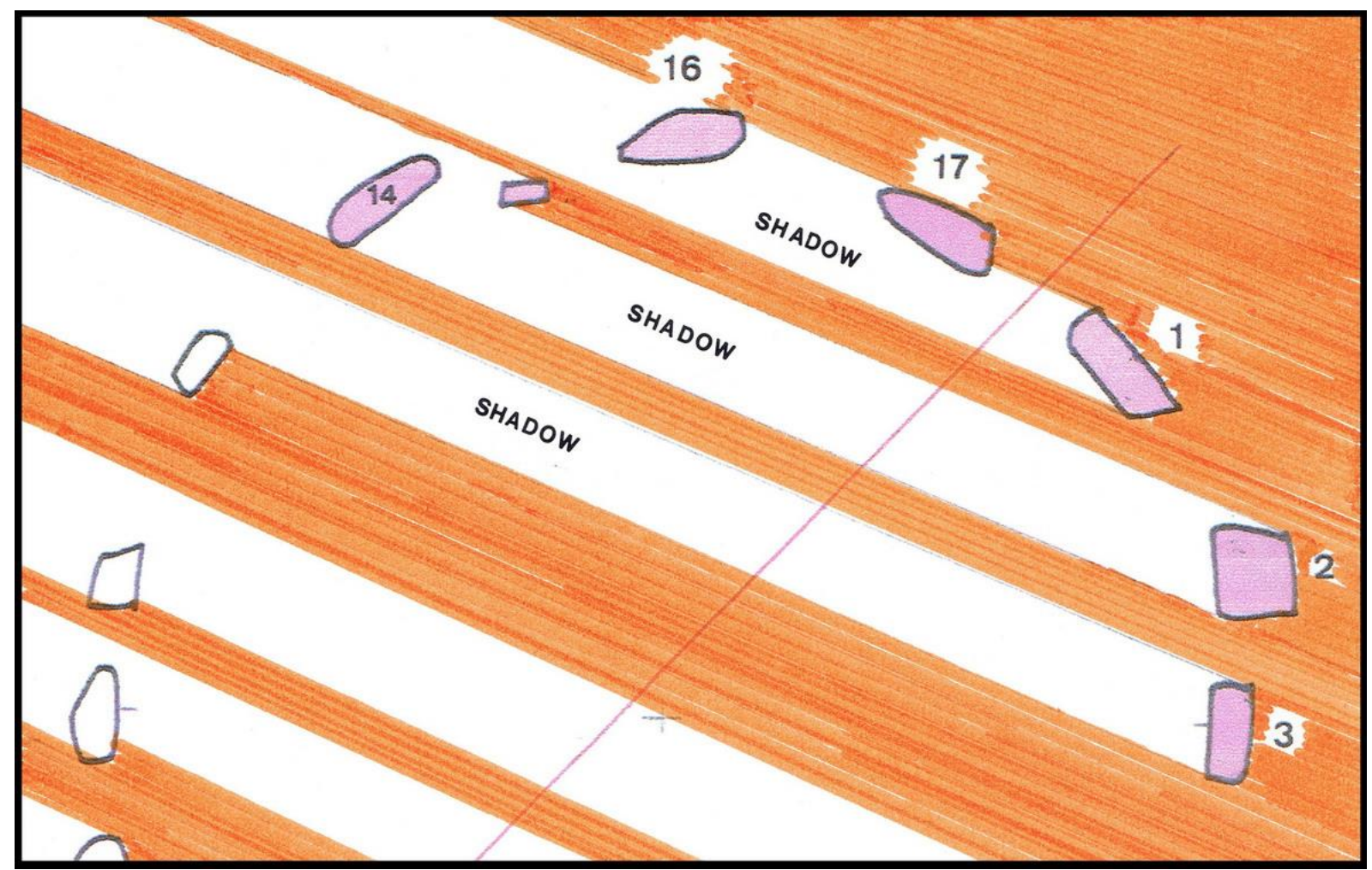

Figure 27. Showing how at sunrise the shadow of Stone 2 initially covers the lozenge stone until a few minutes later when golden sunlight starts to illuminate the latter. In this plan shadows are shown white. 


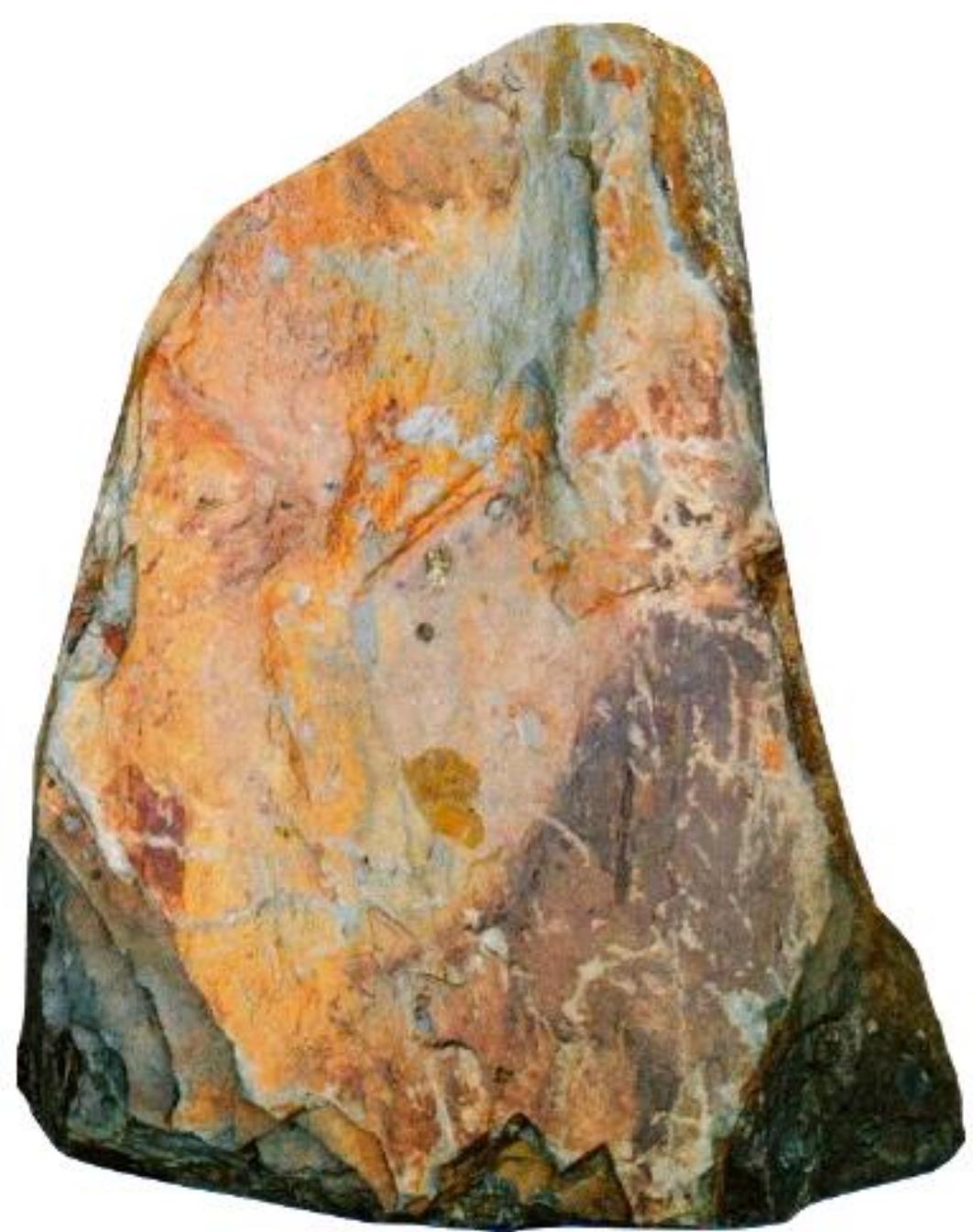

Figure 28. This stone is unusual. It is a black slatey, fine-grained sandstone whose biggest surfaces are colourfully mottled with patches of yellow, orange, red and grey. The colouring is from limonite iron hydroxide (specialist information from geologist Peter Bruck).

This allowed the author to construct a replica and position it for photography at the winter solstice (Figures 29 and 30). From the plan and the photographs one can tell that in midwinter week the shadow of the Franklin Stone encountered the middle of the lozenge stone (Figure 31). Full details are reported in a monograph to be published in 2017.

\subsection{Drombeg summary for the eight festival dates of the agricultural year}

For the agricultural festivals of the summer months the principal carving on the recumbent Stone 9 receives shadows from a sequence of standing stones.

For the festivals of the winter half of the year it is the turn of the lozenge megalith, Stone 14, to accept shadows. Figure 32 summarizes. Note that at the equinoxes both the recumbent stone and the lozenge stone take part simultaneously. In all cases the critical times of day are the minutes beginning with sunrise.

Inter-stone shadow play is proven for all eight festivals of the ancient calendar. This shows that the 8-festival calendar as known from Celtic times had been in use two millennia earlier. Meaden (2009) had already proved this independently through research on 60 long barrows of Neolithic Wessex. 


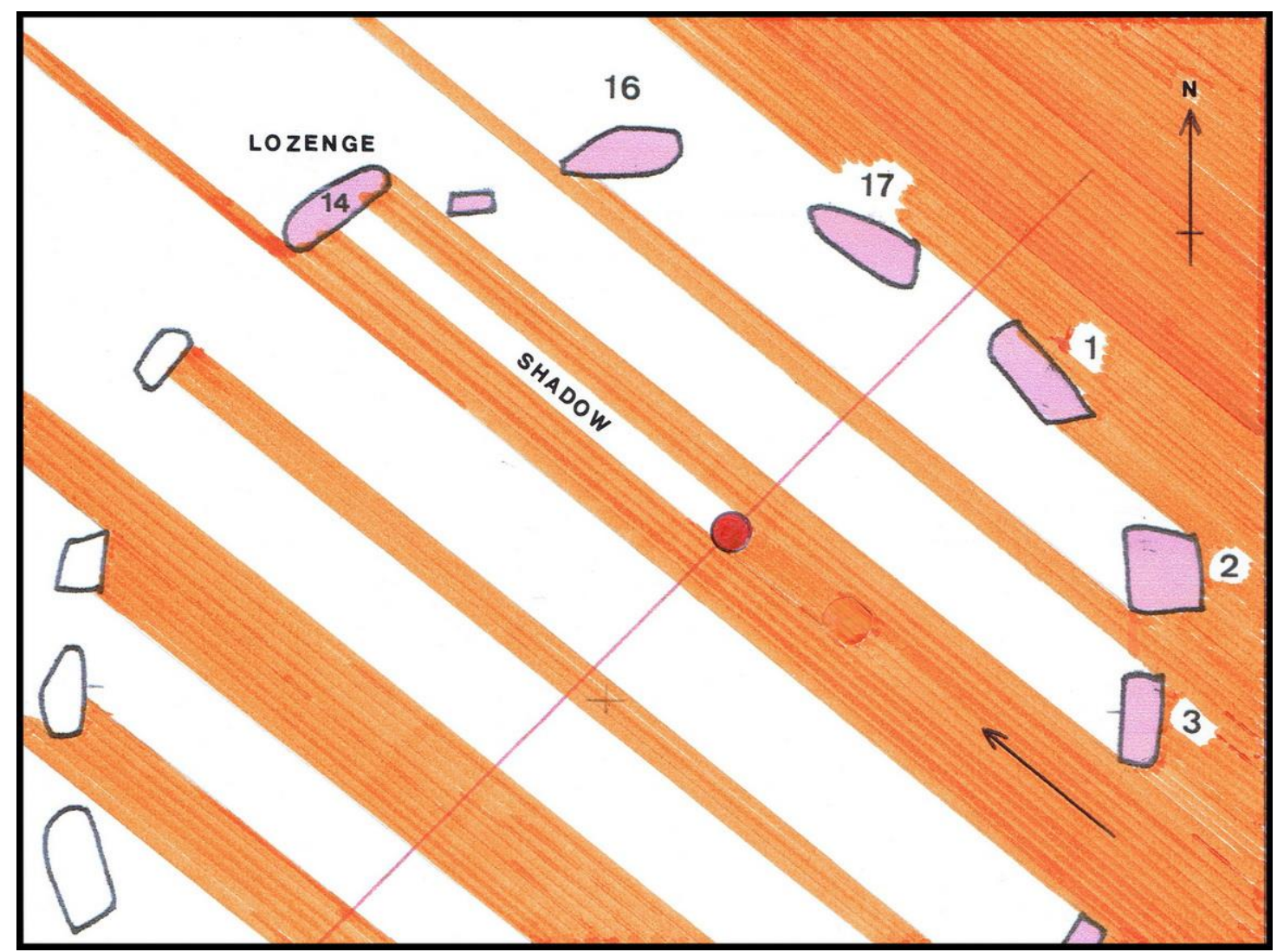

Figure 29. Plan of Drombeg in the light of the rising sun at the winter solstice (in this plan shadows are shown white). The shadows of Stones 3 and 4 both miss the lozenge stone while allowing the sun to shine upon the Franklin Stone (round spot) such that its full shadow arrives in the middle of the lozenge. The Franklin Stone is on the known winter-solstice sunrise line at the point where it crosses the diameter that bisects the recumbent stone and the gap between portal Stones 17 and 1 .

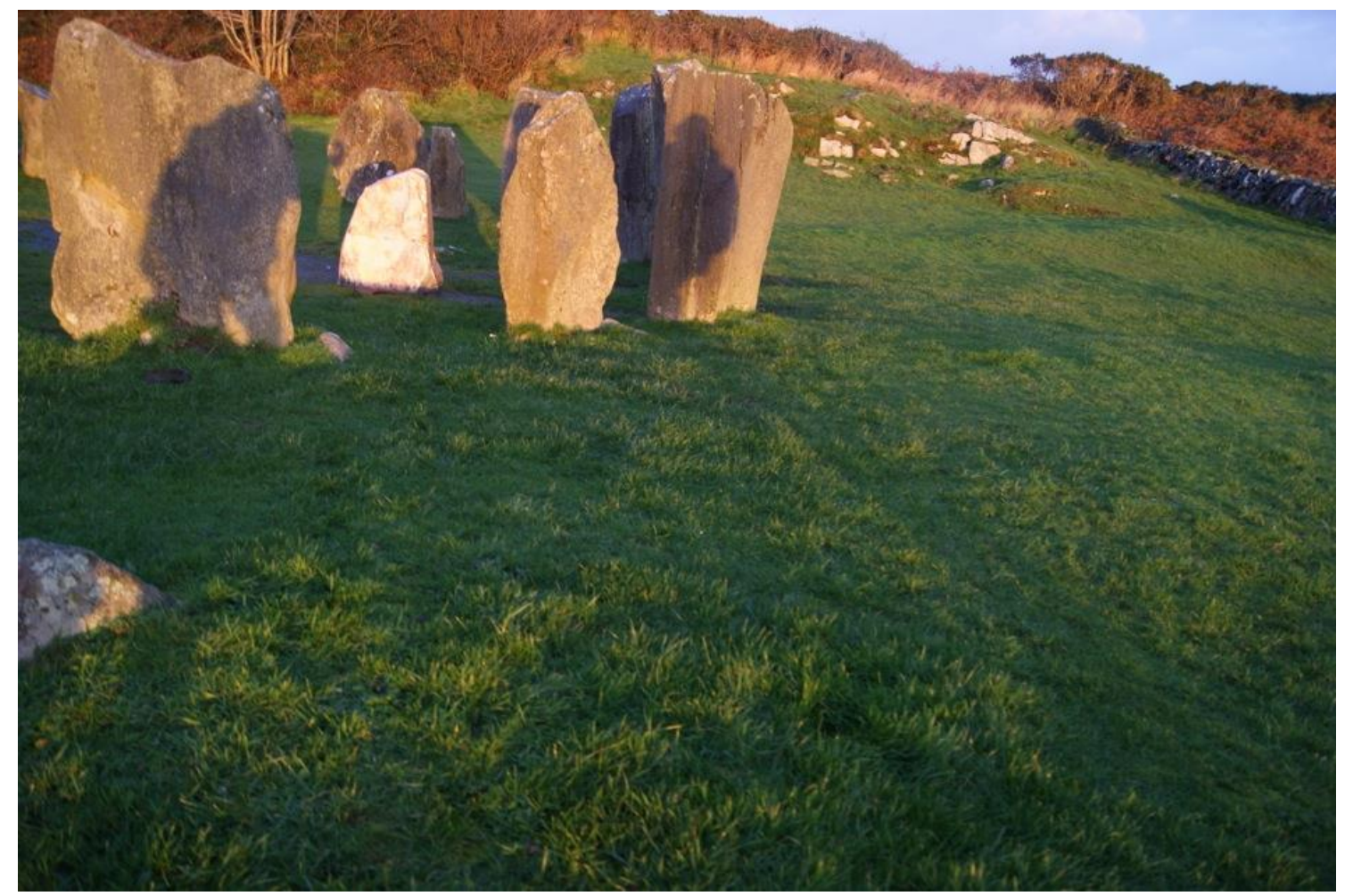

Figure 30. A few minutes after sunrise on 17 December 2013 the shadow of the replica of the Franklin Stone falls centrally upon the lozenge stone. Author's photograph. 


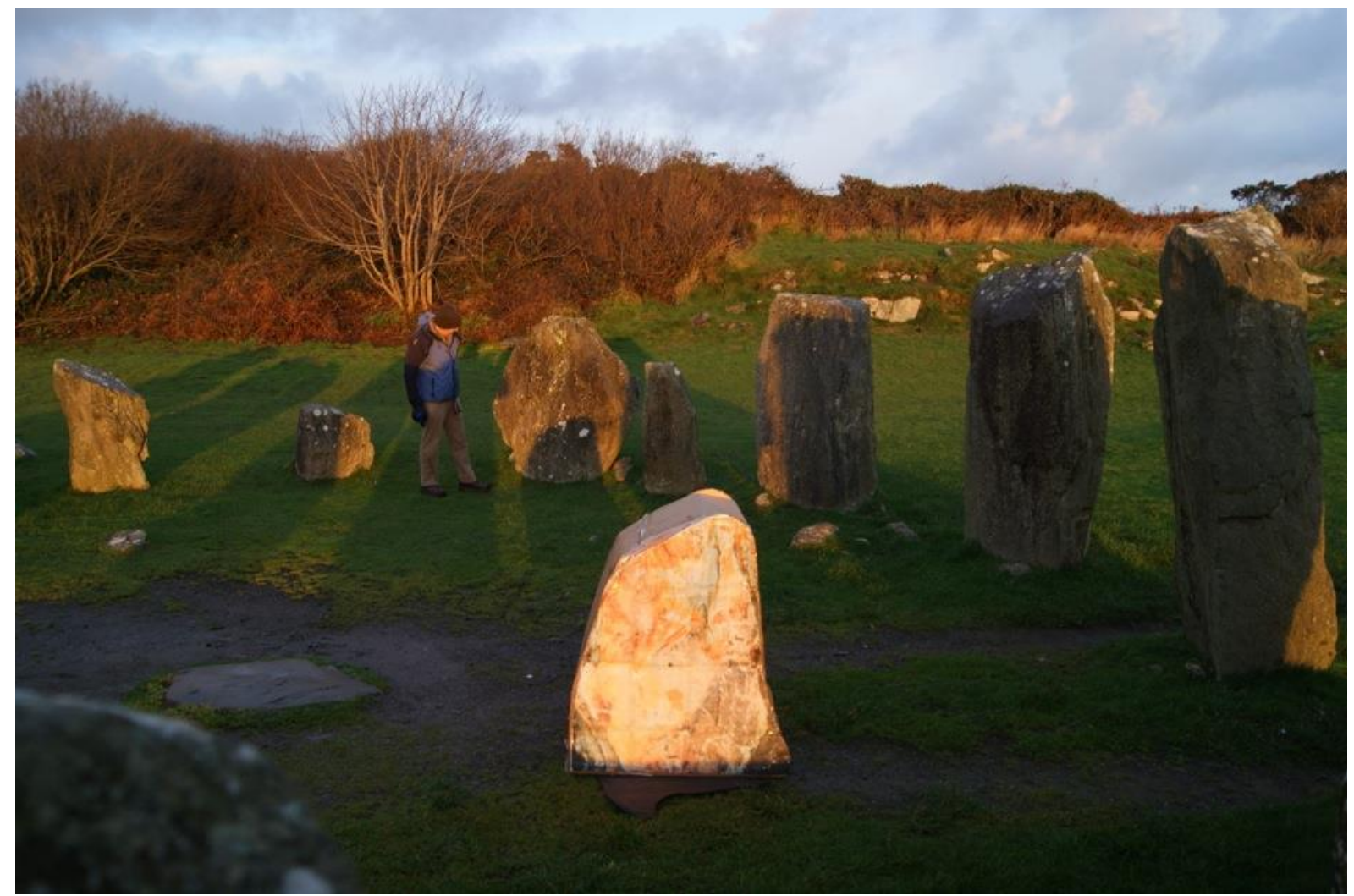

Figure 31. Sunrise in the week of the winter solstice - one of several test reconstructions made on 17 December 2013. Author's photograph.

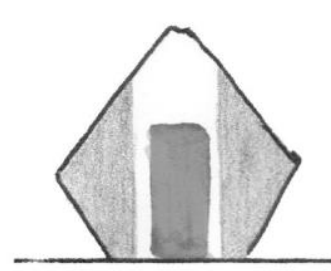

21

Sep

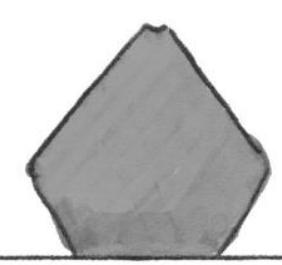

5
Nov
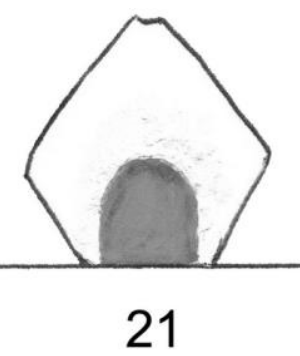

Dec

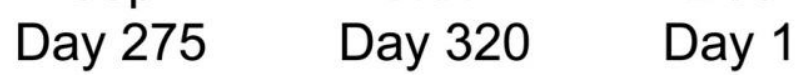

Figure 32. How shadows fall upon the lozenge stone at the festival dates of the winter half of the year.

The precision of the shadow casting shows how exact the dates were intended to be. Thus Imbolc is 5 February (Day 47), not 1 or 2 February. The first day of summer (later called Beltane or May Day) used to be Day 137, 6 May (not the current 1 May). Lughnasadh (Lammas) used to be Day 229, 6 August (not 1 August), and Samhain was formerly Day 320, 5 November (not 31 October or 1 November). The dates for the spring first quarter day (day 92) and the autumn third quarter day (Day 275) were 22 March and 21 September respectively. Celebrations likely often began on the eves of the shadow-casting festival dates.

Sunrise shadows similarly feature at other Neolithic and Bronze Age sites including Knowth, Newgrange, Stonehenge and Avebury. Knowth and Newgrange are treated next, and the others follow in the accompanying paper (Meaden 2016).

It is notable that Knowth supports effects of shadow casting at or close to the spring first quarter and autumn third quarter sunsets as well as sunrises. 


\subsection{Knowth at and near the equinoxes}

The magnificent mound at Knowth covers two stone-lined passages whose directions approximate to, but do not match, the sunrises and sunsets at the spring and summer equinoxes.

A ring of carved recumbent kerbstones surrounds the monument. One fine kerbstone is positioned at each entrance.

Astronomical cosmic knowledge was neatly summarized and stored by what may be termed pictorial intelligence. The author suggests that images and symbols were pecked into stones as a means of safeguarding aspects of basic knowledge that would prove helpful when teaching new generations of aspirants.

In respecting solar behaviour at the approximate equinoxes, passages were built whose directions internally were nearly but not exactly those of equinoctial sunrises and sunsets. In the absence of clocks, lengths of night and day could not be determined with precision. Instead - and because the eight agricultural festivals of the year recur at 45 to 46 day intervals - day-counting would lead to the required March and September dates by tally-stick notching (Section 2.2). Therefore, as regards the approximate equinoxes, what mattered to the planners and worshippers at Knowth were the pre-arranged aspects of the relationship between each entrance recumbent kerbstone and the straight-sided pillar stone standing outside.

\subsubsection{Sunsets and sunrises at Knowth}

Consider the entrance to the western passage of Knowth (Figure 33). It has been observed (e.g., on 16 September 1980 (Brennan 1983: 101); and by author's friends on 20 September 2013 (private communication)) that towards the equinoxes the light of the setting sun casts a shadow of the pillar stone upon the recumbent stone. As the moments of sunset approach the shadow moves along the recumbent stone towards the vertical medial line inscribed on it.

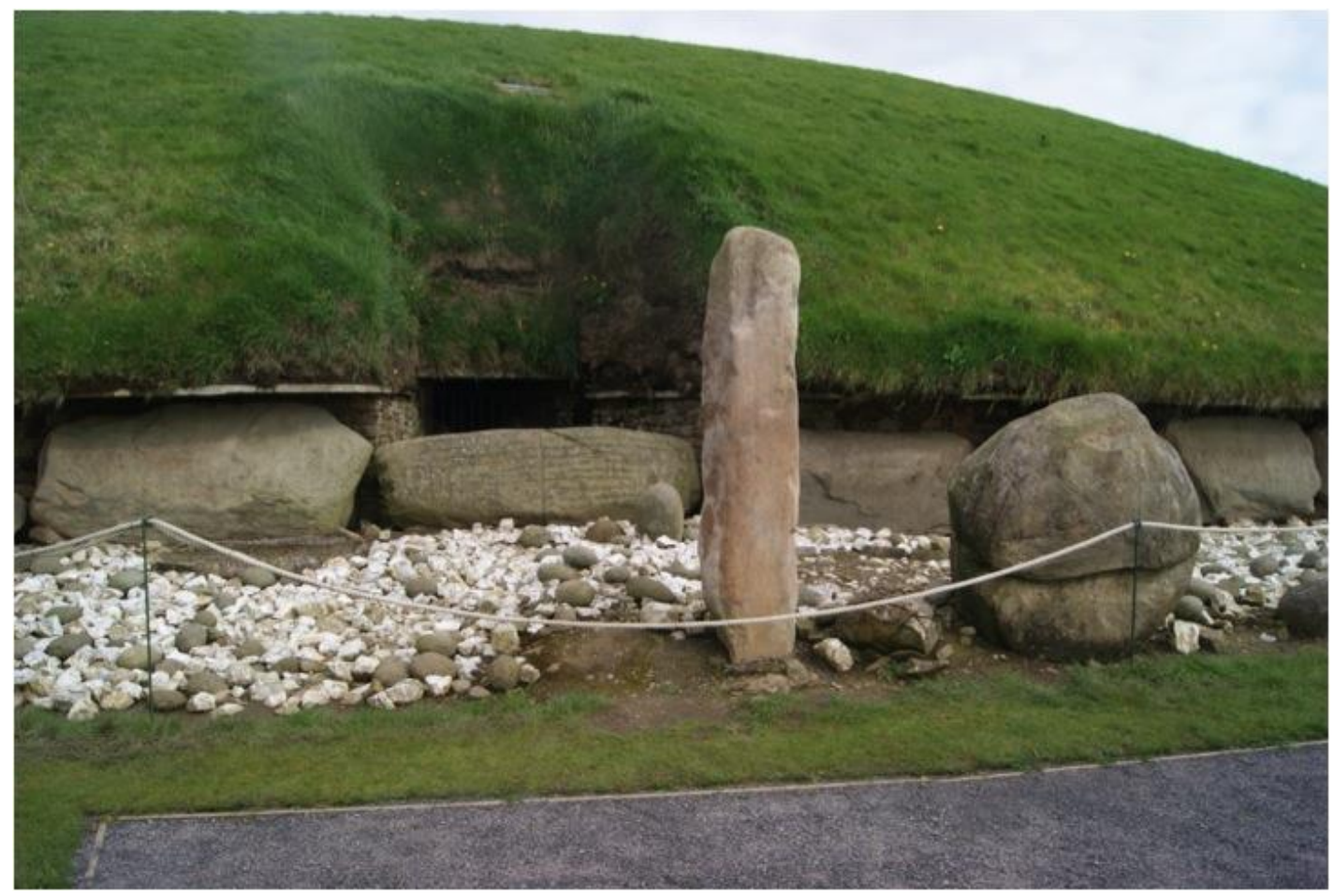

Figure 33. Western side of the great monument at Knowth with its entrance and passageway. On the optimum dates in spring and autumn the setting sun casts a shadow of the pillar stone on the recumbent kerbstone, its target apparently the medial vertical line carved on the latter. Author's photograph. 
It is the same for the eastern facing passage (Figure 34) where there is a recumbent stone with medial vertical line and a narrow straight-sided standing stone that creates union by shadow at the optimum sunrise (Brennan 1983: 103). The sunset-days that mattered to the Knowth community were the days on the 365-day calendar when potentially male-to-female stone-to-stone union was achieved by interactive shadow at the passage entrances.

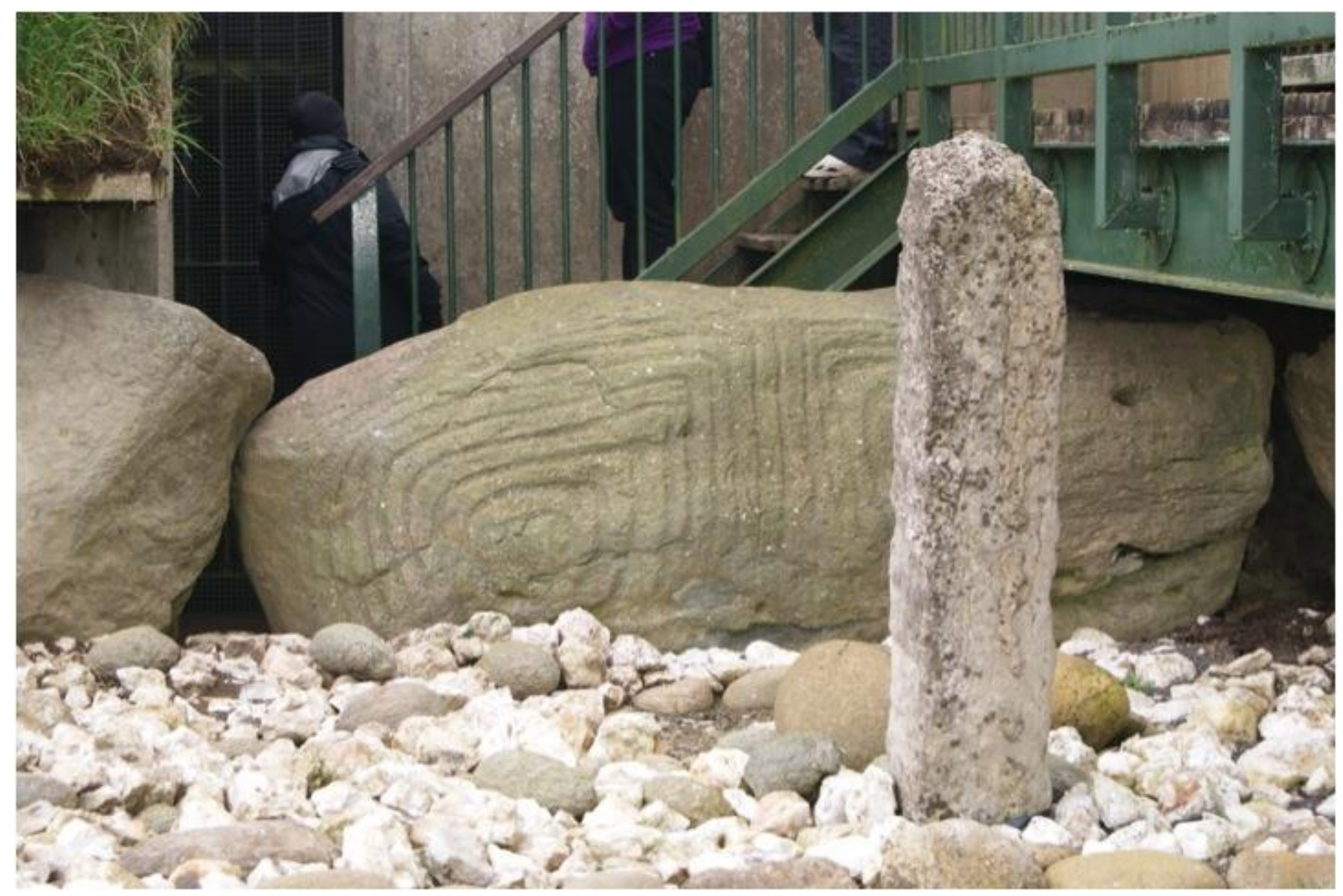

Figure 34. In front of the eastern passage entrance at Knowth lies a kerbstone whose vertical medial line is the target for the shadow of the pillar stone at sunrise on the optimum spring or autumn day planned for it. Author's photograph.

The fact that the passages inside the monument do not duplicate the directions of the equinoctial rising or setting sun is a different matter, and has been addressed by Kate Prendergast (2017).

\subsection{Newgrange winter solstice sunrise alignment}

Newgrange, too, has a finely carved stone positioned in front of its stone-lined passage (Figure 35). The alignment is to the winter solstice sunrise.

The prehistoric community arranged for a stone, GC1, of the great circle (Figure 36) to stand outside the entrance such that its shadow would fall upon the kerbstone K1 at the entrance. It is well known that in midwinter week the light of the rising sun shines through the roof-box above the entrance and reaches the end chamber (O'Kelly 1982). Optimum is the morning of the solstice. It is possible that an additional aim planned for the first minutes after sunrise was that the shadow of the external stone GC1 would meet and cover lozenges engraved on the entrance stone (at the left in the illustration, Figure 35) and, skirting the edge of the triple spirals, move towards the carved vertical line before leaving the bottom of the stone beneath the carved vertical line. That is what it does now, and perhaps did better in the Neolithic and Early Bronze Age. It is interesting that at Drombeg it was the lozenge megalith that received shadows in the winter half of the year (Figure 32) while at Newgrange carved 
lozenges come into play again. Note that at Newgrange ground levels may have changed a little since the site was abandoned. In photographs of a century ago the entrance stone is seen lying slightly angled to the horizontal, so some readjustment has since been done.

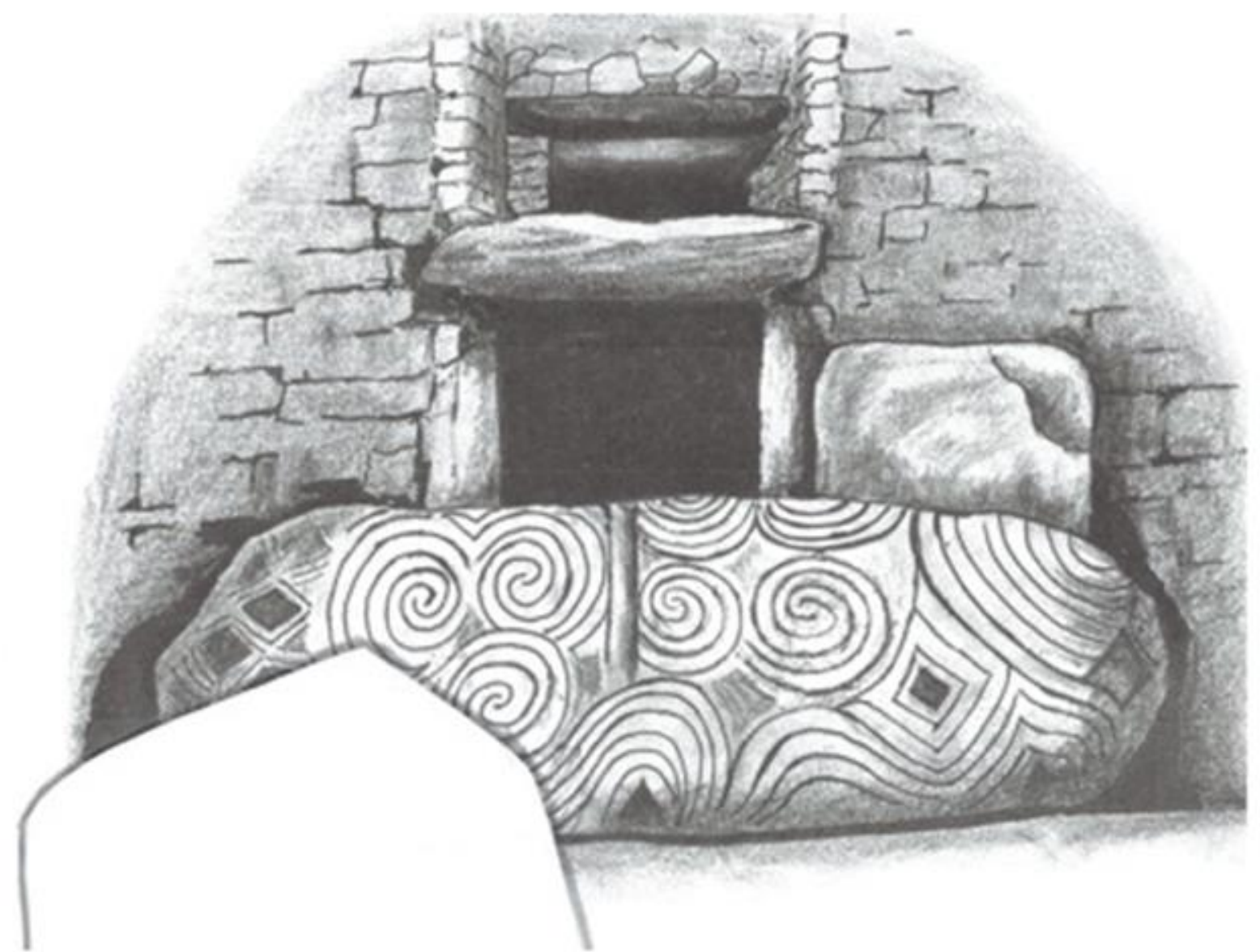

Figure 35. Newgrange, like Knowth, has a splendid carved recumbent kerbstone awaiting a midwinter shadow from the standing stone $\mathrm{GCl}$ of the great circle. At the solsticial sunrise the shadow of GC1 commences by striking the southern end of the recumbent stone K1 for which calculations suggest that, when in prehistoric use, it covered some of the engraved lozenges at the left and the edges of the triple spirals (author's sketch).

Prendergast (1991) examined shadow play at Newgrange by computer simulation for three stones of the great circle using the date of 2015 BCE obtained by Sweetman's 1984 excavation at GC-2 (Sweetman et al. 1985). The results are significant. The shadow casting stones were GC1, GC-1, and GC-2 and the entrance stone, K1, was the receptor. The shadow from GC-2 to the $\mathrm{K} 1$ southern-end lozenges is equinoctial, while that from GC-1 corresponds to the midway intercalary dates near the start of November and February. In this way all five agricultural calendar dates for the winter half of the year are accounted for. Possibly at the other side of the great cairn of Newgrange the dates for the festivals of the summer months were similarly acknowledged with respect to stone K52 at sunset.

Kerbstone K52 with its array of lozenges is a fine carved megalith facing sunset at the summer solstice (Figure 37). The suggestion is that in this region there may have been one or more external stones of the great circle whose purpose was to cast a shadow upon the megalith at the summer solstice sunset and maybe on other dates too. Excavation will tell. 


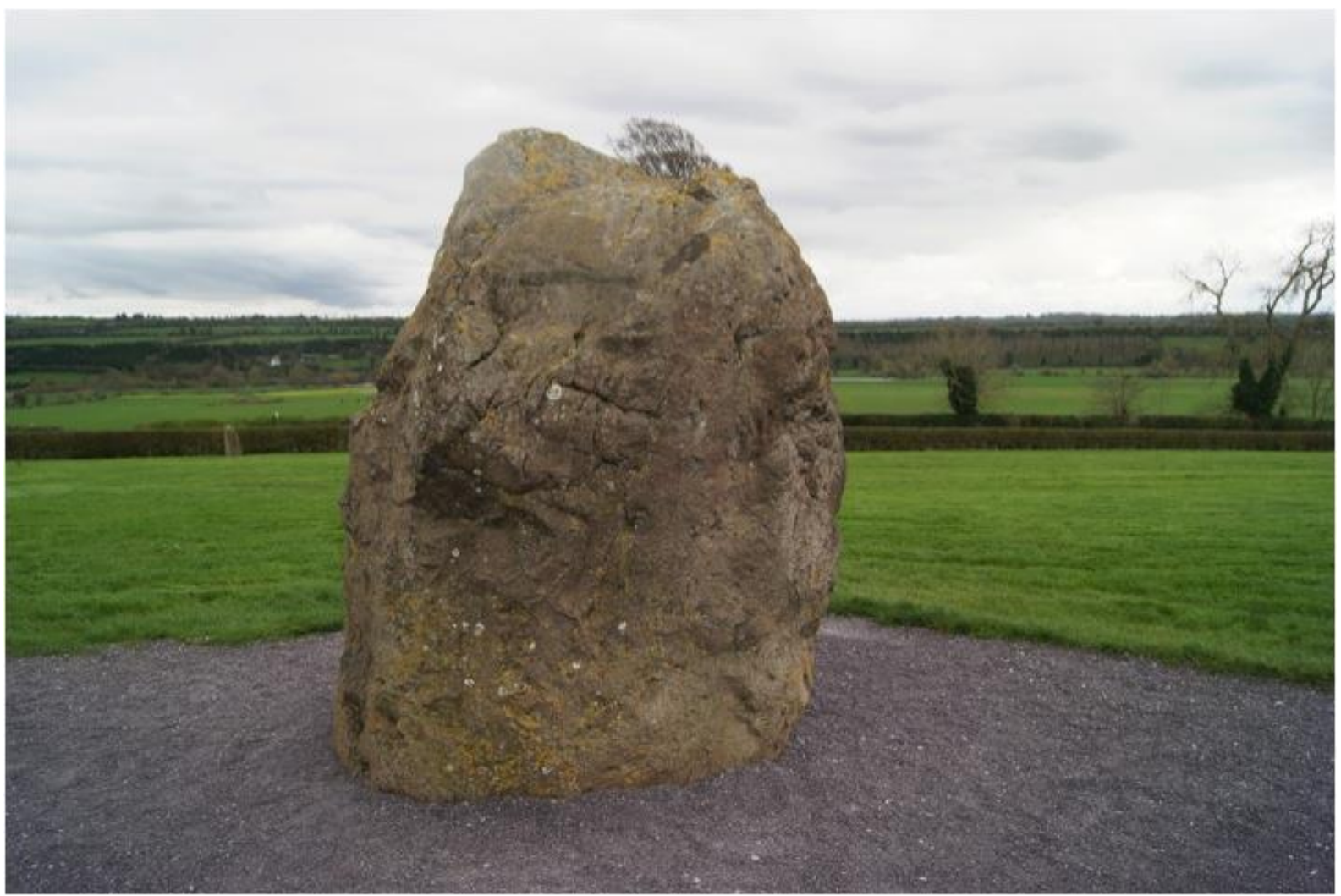

Figure 36. Stone GC1, part of the great circle GC, standing outside kerbstone K1 and the entrance passage to the Newgrange monument (author's photograph).

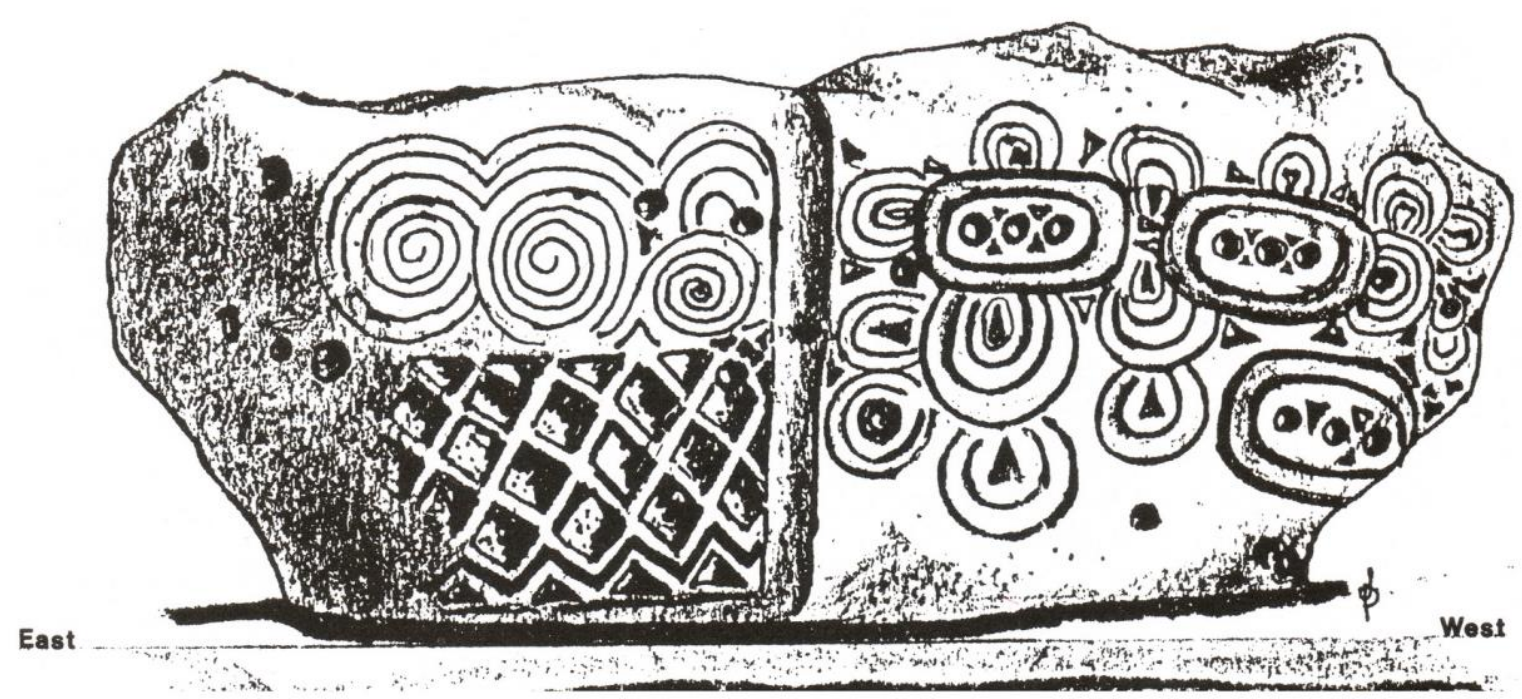

Figure 37. Kerbstone K52 at Newgrange faces the summer solstice sunset. The stone has a line pecked vertically in the middle. This marks the principal axis passing through the monument that follows the line of both the winter solstice sunrise and the summer solstice sunset (author's sketch).

\subsection{North-south lithic union at Templebryan Stone Circle, Ireland}

At the recumbent stone circle at Templebryan near Clonakilty which is $17 \mathrm{~km}$ from Drombeg, a variation on union by shadow takes place annually at midday on the winter solstice. Figure 38 shows how at noon the shadow from the straight-sided southernmost megalith reaches the quartz stone to its north. The latter is positioned off-centre, much as at Drombeg, in the central region of the circle. For most of the rest of the year this midday contact by shadow does not occur because the noontime shadow is too short. 


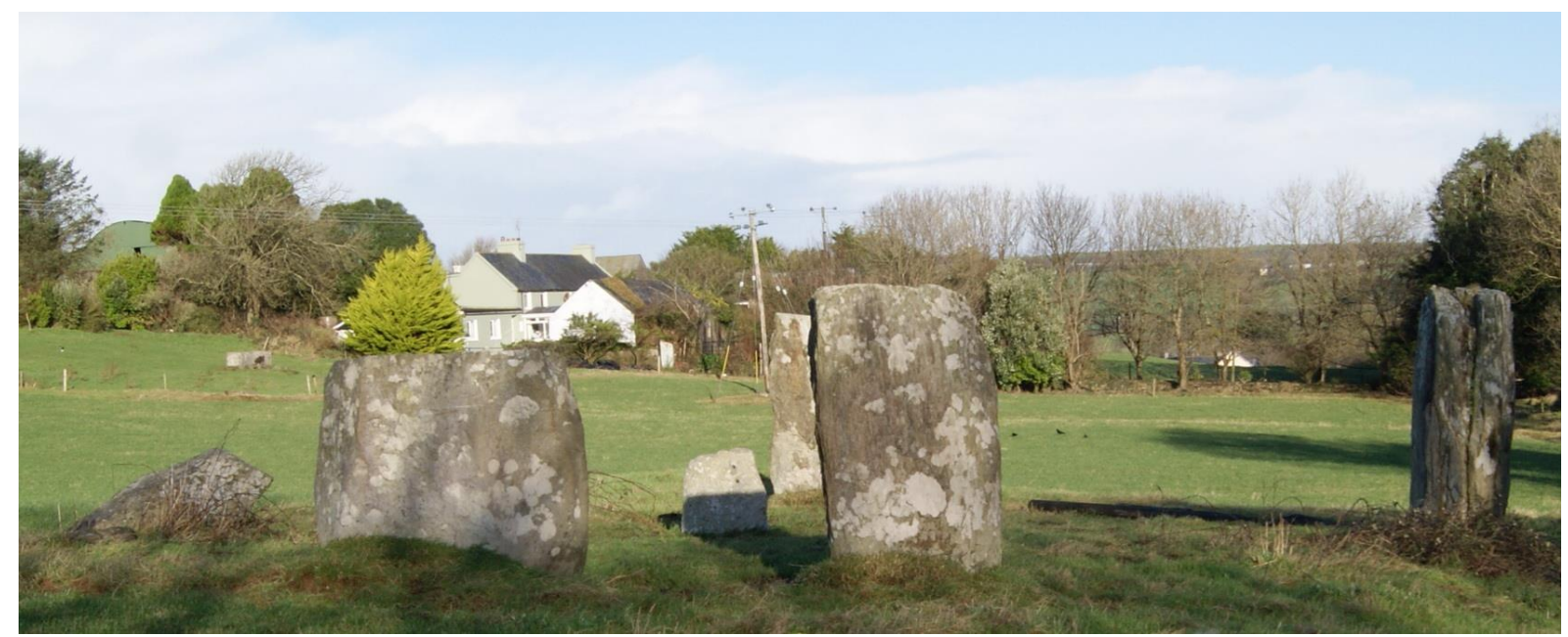

Figure 38. Templebryan Stone Circle: the southerly stone nearest to the camera is tall and straight-sided. At the left is the broad recumbent stone. At noon on 22 December 2013 the shadow of the southerly stone makes contact with the short squat quartz stone in the central area (author's photograph).

Olwyn Pritchard (2016) has recently reported similar research involving pairs of standing stones in West Wales.

At Templebryan because only five perimeter stones remain, and four or more are missing including at least one portal stone, sunrise analysis has not been attempted.

\section{Conclusions}

The facts of this research are that the stones of Drombeg were carefully arranged such that at sunrises on eight key dates of the year - spaced at intervals of 45 or 46 days measured from the solstices - the rising sun would cast shadows of preselected standing stones on to one or other of two particular megaliths. One shadow-casting stone, as recorded and measured in 1903 by Denham Franklin, Justice of the Peace and secretary of the Cork Historical and Archaeological Society, was in 1909 reported to be missing when Captain Boyle Somerville visited. It is suggested that the flat-bottomed standing stone found in 2012 near Drombeg House half-a-kilometre away is the missing stone.

In the first minutes after sunrise as the sun moves, the shadows move, and each target of interest - depending on the chosen date for each particular shadow-covered stone progressively gets illuminated by sunshine of increasing strength.

Examination suggests that two fundamental measures using lithic symbology, either static or dynamic, had been prepared at Drombeg in order to make the impact dramatic and meaningful. One made use of familiar well-loved symbols and shapes, the dynamic one involved cosmic drama.

The first explores the use of lithic images including symbolic outlines and engravings to transmit meanings understood by devoted communities. The symbols are lozenge-shaped stones and pillar-type forms, besides also engraved symbols and natural geological lithic forms. The result is instinctive indications of the feminine and the masculine as Drombeg excavator Edward Fahy (1959: 21, 23, 25) had foreseen. This understanding helps to introduce explanations when it comes to interpreting underlying aspects of the intentions for the stone circle at Drombeg, and the external stones and major kerbstones at Knowth and Newgrange.

For Drombeg, citing Fahy (1959: 21), "Stone 15, whether by design or by accident, presents a curiously phallic outline which, taken in conjunction with the lozenge shaped boulder, and the Avebury analogy, ... tends to suggest that at Drombeg we are dealing with another instance of symbolism which by its nature ought to be connected with a fertility cult". 
He further emphasizes (Fahy 1958: 25) that "the axial orientation of the circle confirms that the midwinter sunset played a major role in the religious practices of its builders who, if we admit the proffered interpretation of Stones 15 and 14 as male and female symbols, would appear to have practised a fertility cult".

The present study, beginning in 2012, also considered the watchable dramas that can still be witnessed at Drombeg today, in which solar movement at preselected optimal sunrise dates creates shadows that cross the surface of a carefully positioned lozenge-shaped standing stone and the recumbent stone. Such action is another means by which non-literate societies could express their spirituality.

A few earlier studies have been made that examined effects of sunlight and shade caused by standing stones. In October 1985 the author began the present research on the concept of shadow casting at Stonehenge that would occur at the summer solstice. His first research photographs of shadow casting by the Heel Stone at Stonehenge in the week of the summer solstice were taken in 1986, and the first published solstice-week photographs, dated 1987 and 1989, followed later (Meaden 1992: plates 13, 14 and 15; and Meaden 1997). Meanwhile, unknown to the author until 2015, Prendergast (1991: fig. 5) reported his thesis research study of shadow casting at Newgrange for the five dates that are the winter solstice, the equinoxes and the intercalary dates between. Bradley (1989), rather differently, discussed matters of darkness and shade in the interiors of megalithic-chambered tombs using examples from the south of Brittany. Pasztor et al. (2000: 111-113) and Pasztor (2011) also considered aspects of light, brightness and shade in the middle of Stonehenge.

Examined in detail in the present paper are questions arising from the sophisticated design of the Drombeg Stone Circle. Dramatic enchantment proceeds from the shadow motion produced by the light of the moving sun in the minutes after its rising. This follows from the deliberately irregular yet intentional positioning of circumferential stones related to specific calendar dates when a series of shadows at sunrise - cast by straight-sided stones - fall upon one or other of two particular megaliths. This succeeds to perfection on the eight festival dates known from the traditional agricultural calendar. It explains how these calendar dates were encoded into the monument, and are here decoded by the present research.

The story of moving sun and phallic shade unfolds like the drama of a silent movie expressed in wordless mime. By linking stones that represent the sexes, it is proposed that interpretation was through the concept and desire for fertility - an understandable core feature of life for farming communities. The vision would have been unmistakable and heartening for hard-working peoples who toiled the land and suffered the vicissitudes of changing fortune that came with the arrival of seasonal and unseasonal weather.

The results of this research accord with Irish archaeological judgment. Thus Prof. Ronald Hicks (1985: 72-73) writing of astronomical traditions of ancient Ireland and Britain: "In early monuments ... there are tales that associate stone circles and henges with the old crossquarter days and the solstices, some of these associations being in the form of place names, like the proposal by Ó Ríordáin and Daniel (1964: 16) that the name Newgrange is an anglicization of An Uamh Gréine, meaning the cave of the sun."

Hicks (1985: 79) concluded "this strongly suggests that it was an attempt to symbolize the midwinter sun impregnating the earth so that it would again bring forth food for the people." As a consequence, and for other reasons involving local mythology, he determined "it is hard to resist the suspicion that the agricultural cycle, and thus the year, the seasons, and astronomy are intimately involved in it."

Perceptions of a lost spirituality are being rediscovered in the art and religion of the British and Irish Neolithic and Early Bronze Age. The role of the sky and sun in archaeology archaeoastronomy - has developed increasingly learned rigour recently and provides insights into beliefs and practices of prehistoric cultures as, for instance, in the volume edited by Silva 
and Campion (2015). It turns out that the Drombeg explanation may lie with the classic cosmological fertility drama which is the hieros gamos. Thus, Edward Fahy (1959: 20-21) could be right (Section 3.3) in proposing a connection with a fertility cult. For example, the ancient Irish in creating a situation in which solar energy replaces the initial shadow may have been contemplating "Sun and Earth" as primary divinities much as in India where there is a "three-day fecundity festival celebrated by the Hindus in East India known as Ambabuchi occurring on, or a day later to, the summer solstice". In fact, these festivalgoers hold that "the sunrays are believed to fertilize the Mother Earth" (Das 2014: 31). In another example of surviving age-old festivals Das (2014: 31) relates that there is the annual Sarhul fertility festival of proto-Australoid tribals in Jharkhand that "celebrates the marriage between the mother earth and the father sky" and of "the earth becoming fertile ... which is signalled by the blossoming of the Sal tree (Shorea robusta)".

What had been intelligently built into Irish and British monuments long ago using symbolic artistry and cosmic motion is being deciphered in the twenty-first century and clarified at various sites through interdisciplinary analyses.

In another paper related findings are presented for Avebury and Stonehenge (Meaden 2017a). A monograph giving more detail about the Drombeg discoveries is awaiting publication (Meaden 2017b). The research continues, in a continual refining of the sunrise observations for the optimum dates of the calendar.

\section{Acknowledgments}

The author wishes to thank Professor Luiz Oosterbeek for his considerable encouragement when hearing the author lecture on this subject in July 2012 in Sardinia at the International Summer School on European Prehistory. Thanks too, to the academic support by members of the audience at the UISPP session at which this research was presented as a lecture at Burgos, Spain, in September 2014. The author also thanks Linda Angelina Howley and Mr John Davies, the author's connections in County Cork for their aid, besides several Drombeg residents who, as well as their parents, reported seeing the alleged Franklin Stone standing near Drombeg House decades ago in the twentieth century. Finally, farmer Mr Dan Murphy of Shannonvale near Clonakilty, County Cork, who very kindly told the author of the stone-to-quartzstone union by shadow that takes place at midday at the winter solstice at the Templebryan Stone Circle on his land.

\section{References}

Bender, H. 2017, The Star-Beings and stones: Petroforms and the reflection of Native American cosmology, myth and stellar traditions. Journal of Lithic Studies, 4(4): 79118 p. doi: $10.2218 /$ jls.v4i4.1918

Bradley, R. 1989, Darkness and light in the design of megalithic tombs. Oxford Journal of Archaeology. 8, 251-259. doi:10.1111/j1468-0092.1989.tb00205.x

Brennan, M. 1983, The Stars and the Stones. Thames and Hudson, London, 208 p.

Burkert, W. 1985, Greek Religion. Blackwell, Oxford, 493 p.

Childe, V.G. 1952, Prehistoric Communities of the British Isles. Chambers, London, $274 \mathrm{p}$

Cleal, R.M.J., Walker, K.E., \& Montague, R. 1995, Stonehenge in its Landscape: Twentieth Century Excavations. English Heritage, London, 618 p.

Das, S. 2014, Unknown Civilization of Prehistoric India. Kaveri Books, New Delhi, 184 p. 
Eogan, G. 1986, Knowth and the Passage Tombs of Ireland. Thames and Hudson, London, $247 \mathrm{p}$.

Fahy, E.M. 1959, A recumbent stone circle at Drombeg, in County Cork. Journal of the Cork Historical and Archaeological Society, 64: 1-27.

Franklin, D. 1903, Stone circle near Glandore, Co. Cork. Journal of the Cork Historical and Archaeological Society, 9: 23-24.

Gimbutas, M. 1989, The Language of the Goddess. Harper and Row, San Francisco, 388 p.

Gimbutas, M. 1991, The Civilization of the Goddess: The World of Old Europe. Harper Collins, San Francisco, 529 p.

Heggie, D.C. 1981, Megalithic Science: Ancient Mathematics and Astronomy in Northwest Europe. Thames and Hudson, London, 256 p.

Hicks, R. 1985, Astronomical traditions of Ancient Ireland and Britain. Archaeoastronomy, 8: 70-79.

Keiller, A., \& Piggott, S. 1936, The recent excavations at Avebury. Antiquity, 10: 417-427. doi:10.1017/S0003598X00012114

Krupp, E.C. 1997, Skywatchers, Shamans and Kings. Wiley, New York, 364 p.

Meaden, G.T. 1992, The Stonehenge Solution. Souvenir Press, London, 224 p.

Meaden, G.T. 1997, Stonehenge: The Secret of the Solstice. Souvenir Press, London, 168 p.

Meaden, G.T. 1999, Secrets of the Avebury Stones. Souvenir Press, London, 152 p.

Meaden, G.T. 2008, A contribution to the understanding of spirals and lozenges in the rock art of Neolithic Britain and Ireland. In: Symbolism in Rock Art: L'Union Internationale des Sciences Préhistoriques et Protohistoriques (UISPP), Lisbon, 2006 (Coimbra, F., \& Dubal, L., Eds.), British Archaeological Reports International Series Vol. 1793, Archaeopress, Oxford: p. 13-17.

Meaden, G.T. 2009, Long barrows of North and Mid Wessex: A Fresh Appraisal of the Settings, Orientations and Monumental Relationships, and Reconstruction of a Neolithic Calendar. MSc thesis, Department of Continuing Education, Oxford University, Oxford, $93 \mathrm{p}$.

Meaden, G.T. 2017a, Stonehenge and Avebury: Megalithic shadow casting at the solstices at sunrise. Journal of Lithic Studies, 4(4): 39-66 p. doi:10.2218/jls.v4i4.1920

Meaden, G.T. 2017b, Stonehenge, Avebury and Drombeg Stone Circles Deciphered: The Archaeological Decoding of the Core Symbolism and Meanings. Lambert Academic Publishing, Saarbrücken, $228 \mathrm{p}$.

O’Kelly, M.J. 1982, Newgrange: Archaeology, Art and Legend. Thames and Hudson, London, $240 \mathrm{p}$.

Ó Ríordáin, S.P., \& Daniel, G. 1964, New Grange and the Bend of the Boyne. Thames \& Hudson, London, 218 p.

Pásztor, E., Roslund, C., Juhász, Á., \& Dombi, M. 2000, Simulation of Stonehenge. In: Virtual Reality in Archaeology (Book + CD-ROM edition) (Barceló, J.A., Forte, M. \& Sanders, D. Eds.), British Archaeological Reports, International Series Vol. 843, Archaeopress, Oxford: 111-113 p. 
Pásztor, E. 2011, The harmony of the immaterial and the material in prehistoric monuments: Investigating ancient light and shadow interaction, In: Experiments with Past Materialities (Gheorghiu D., \& Children, G., Eds.), British Archaeological Reports International Series Vol. S-2302. Archaeopress, Oxford: p. 90-109.

Prendergast, F.T. 1991, Shadow casting phenomena at Newgrange. Survey Ireland, 1991(Nov.): 1-18 (page 15 for shadow sketches).

Prendergast, K. 2012, The Neolithic monument of Newgrange in Ireland: A cosmic womb. In: Archaeology of Mother Earth sites and sanctuaries through the Ages (Meaden, G.T., Ed.), British Archaeological Reports International Series Vol. 2389, Archaeopress, Oxford: p. 57-64.

Prendergast, K. 2017, Knowth passage-grave in Ireland: An instrument of precision astronomy? Journal of Lithic Studies, 4(4): 67-77 p. doi:10.2218/jls.v4i4.1921

Pritchard, O. 2016, Shadows, stones and Solstices. Journal of Skyscape Archaeology, 2(2): 145-164.

Ruggles, C. 1999, Astronomy in Prehistoric Britain and Ireland. Yale University, New Haven, $286 \mathrm{p}$.

Silva, F., \& Campion, N. (Eds.) 2015, Skyscapes: The role and importance of the sky in archaeology. Oxbow Books, Oxford, 210 p.

Smith, Isobel F. 1965, Windmill Hill and Avebury: Excavations by Alexander Keiller. Oxford University Press, Oxford, 265 p.

Somerville, B.T. 1909, Notes on a stone circle in County Cork. Journal of the Cork Historical and Archaeological Society, 15: 105-108. doi:10.1038/081126b0

Sweetman, P.D., O’Sullivan, V.R. Gunn, H.M., Monk, J., Donnabháin, B.Ó., \& Scannell, M. 1985, A Late Neolithic/Early Bronze Age pit circle at Newgrange, Co. Meath.

Proceedings of the Royal Irish Academy. 85(C): 195-221.

URL: http://www.jstor.org/stable/25506131 